Article

\title{
Analysis of Electrochemical Impedance Spectroscopy on Zinc-Air Batteries Using the Distribution of Relaxation Times
}

\author{
Robert Franke-Lang *(D) and Julia Kowal (D) \\ Electrical Energy Storage Technology, Technical University of Berlin, 10587 Berlin, Germany; \\ julia.kowal@tu-berlin.de \\ * Correspondence: robert.franke@tu-berlin.de
}

check for updates

Citation: Franke-Lang, R.; Kowal, J.; Analysis of Electrochemical Impedance Spectroscopy on Zinc-Air Batteries Using the Distribution of Relaxation Times. Batteries 2021, 7, 56. https://doi.org/10.3390/

batteries7030056

Academic Editor: Yair Ein-Eli

Received: 26 April 2021

Accepted: 28 July 2021

Published: 18 August 2021

Publisher's Note: MDPI stays neutral with regard to jurisdictional claims in published maps and institutional affiliations.

Copyright: (c) 2021 by the authors. Licensee MDPI, Basel, Switzerland. This article is an open access article distributed under the terms and conditions of the Creative Commons Attribution (CC BY) license (https:// creativecommons.org/licenses/by/ $4.0 /)$.
Abstract: Zinc-air batteries could be a key technology for higher energy densities of electrochemical energy storage systems. Many questions remain unanswered, however, and new methods for analyses and quantifications are needed. In this study, the distribution of relaxation times (DRT) based on ridge regression was applied to the impedance data of primary zinc-air batteries in a temperature range of $253 \mathrm{~K}$ and $313 \mathrm{~K}$ and at different State-of-Charges for the first time. Furthermore, the problem of the regularization parameter on real impedance spectroscopic measurements was addressed and a method was presented using the reconstruction of impedance data from the DRT as a quality criterion. The DRT was able to identify a so far undiscussed process and thus explain why some equivalent circuit models may fail.

Keywords: DRT; zinc-air batteries; EIS; regularization; ridge regression; capacity

\section{Introduction}

The restructuring of electrical energy production to renewable energies is accompanied by a volatile energy generation and requires energy storage in order to regulate production and demand. In the field of electrochemical energy storage, lithium-ion batteries (LIBs) are probably the best-known electrical energy storage technologies [1], but they have significant shortcomings in terms of cost, safety, and specific capacity. Zinc-air batteries (ZABs), for example, are comparatively cheaper, safer, and have a three times higher theoretical gravimetric capacity of about $820 \mathrm{Ah} \mathrm{kg}^{-1}$ based on the active material compared to an $\mathrm{LiCoO}_{2} \mathrm{LIB}$. The reason is mainly due to the working principle of ZABs, as two electrons are moved per mass transfer and the required oxygen is extracted from the ambient air. Despite the principle rechargeability of the technology, ZABs exist commercially only as primary batteries and are used mainly in hearing aids [2]. A suitable electrocatalyst for both an efficient oxygen reduction reaction (ORR) and an oxygen evolution reaction (OER) cycle has not yet been found [3-5], nor has a filter that regulates the oxygen and the humidity from the ambient air been developed [6,7]. The dendrite growth [8-11], the shape change [12-14], the passivation of the anode [15-18] and the zincate transport into the gas diffusion layer (GDL) during charging [19] are also critical parameters for rechargeability. In order to prevent such processes, it is necessary to gain a fundamental understanding of the reactions and their interactions [20]. One common method for this is the electrochemical impedance spectroscopy (EIS) [21], which is used for material optimization and modeling besides process analysis and quantification [22-29]. In addition to the visual evaluation of the impedance data, fitted equivalent circuit models (ECM) are used for quantification [21]. However, different combinations of equivalent circuit elements can produce the same results [30], which can lead to misinterpretations [31], especially if the type and the number of the involved processes are not clearly determined. Furthermore, the separation and the readability are hardly given for similar or overlapping processes, e.g., the negative electrode is similar to the positive electrode in character, then the time constants of both electrodes can influence the same measuring points in the 
frequency range. Therefore, the interpretation of the impedance data using the universal distribution of relaxation times (DRT) approach is becoming increasingly popular [32-39], since no deeper prior knowledge of chemical-physical or electrical models is required and superimposed processes can possibly be distinguished.

In this article, the DRT was applied to commercial zinc-air primary cells for the first time. For this purpose, the primary cells were measured by EIS at temperatures between $253 \mathrm{~K}$ and $313 \mathrm{~K}$ and different States-of-Charges (SoCs). The SoCs were targeted by four different discharge currents during the galvanostatic discharge. In addition to the process analysis, the capacity of the primary ZABs was also discussed. Furthermore, the Gaussian probability distribution function was presented for the quantification of the individual processes, which were identified from the DRT. For the determination of the regularization parameter, used in the ridge regression for solving the DRT, a method was implemented to compare the reconstructed spectrum with the EIS measurement. The use of a brute force algorithm coupled with a minimization algorithm provided reliable values. The issue of varying the regularization parameter was also critically discussed in this study.

\section{Materials and Methods}

\subsection{Electrochemical Impedance Spectroscopy}

The EIS measurements were performed on commercial ZABs of the type PR48 with a nominal capacity of about $300 \mathrm{mAh}$. For one experiment, 4 cells from a blister were used for the characterization and 2 cells were used for preliminary studies, where the capacity was determined (see Table 1) by using a constant discharge current (applied by a Neware BTS5V10mA potentiostat) in a climate chamber (Binder MK 56) related to the defined current and the temperature combinations. The primary investigation includes the combination of the temperatures of $273,283,294,303$, and $313 \mathrm{~K}$ with $3,4,5$, and $6 \mathrm{~mA}$ discharge currents, respectively. For the current of $3 \mathrm{~mA}$, the temperatures of $253 \mathrm{~K}$ and $263 \mathrm{~K}$ were also examined. The cells were connected to a custom four-wire measurement holder and were measured with a PARSTAT ${ }^{\circledR}$ MC PMC-2000A potentiostat/galvanostat. First, the cells were unsealed and rested at least for $5 \mathrm{~h}$ at a defined temperature until they reached the open cell voltage (OCV) of $1.45 \mathrm{~V}$. Then, $10 \% \mathrm{SoC}$ was gradually discharged from the cells and after resting up to $1.45 \mathrm{~V}$, a galvanostatic EIS was performed. This procedure was repeated until a cut-off voltage of $0.9 \mathrm{~V}$ was reached and is shown in Figure 1. The EIS measurement was carried out between $50 \mathrm{mHz}$ and $1.75 \mathrm{MHz}$ with a current amplitude of $A_{\mathrm{RMS}}=1.5 \mathrm{~mA}$ and a superimposed discharge DC current of $3 \mathrm{~mA}$. A total of 10 values per decade were recorded and the average of 3 consecutive cycles was taken, resulting in an $\mathrm{SoC}$ change of less than $0.15 \%$. In an additional study for investigating the inhomogeneous discharge behavior during the first $10 \% \mathrm{SoC}$ discharge, as shown in (Figure 1a), the frequency range of the EIS measurement was reduced to $10 \mathrm{~Hz}$ and $1 \mathrm{MHz}$, which decreased the measurement time from about $7.5 \mathrm{~min}$ to $20 \mathrm{~s}$. Contrary to the routine described above, the cells were only discharged by the superimposed DC current of the EIS measurement, which was repeated permanently.

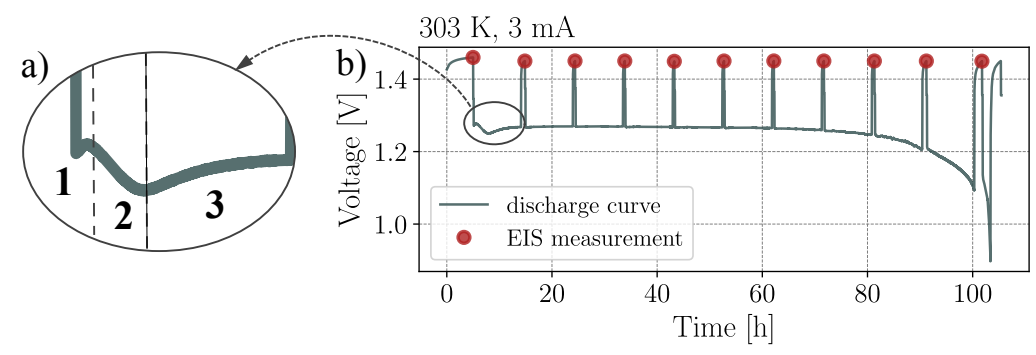

Figure 1. Discharge curve of a ZAB (b) at $303 \mathrm{~K}$ with a constant current of $3 \mathrm{~mA}$. The red circles indicate the point where the EIS measurement was taken. (a) Illustrates the inhomogeneous discharge behavior separated in three different sub-processes during the discharge of the first $10 \% \mathrm{SoC}$. 


\subsection{Distribution of Relaxation Times}

The basic idea of the DRT is the approximation of the measured data by an infinite series of overlapping resistor and capacitor (RC) circuits in parallel form. The weighting of the individual terms is described by a distribution function:

$$
\mathrm{Z}_{\mathrm{DRT}}(\omega)=R_{\infty}+\int_{0}^{\infty} \frac{h(\tau)}{1+\mathrm{j} \omega \tau} \mathrm{d} \tau .
$$

Normalizing the distribution function to the total polarization of the system yields the more common representation of the DRT:

$$
\mathrm{Z}_{\mathrm{DRT}}(\omega)=R_{\infty}+R_{\mathrm{p}} \int_{0}^{\infty} \frac{g(\tau)}{1+\mathrm{j} \omega \tau} \mathrm{d} \tau .
$$

The solution of the distribution function $g(\tau)$ corresponds to a deconvolution in the frequency domain. However, as the distribution function is not uniquely defined, various approaches including the Fourier transform [34,40,41], Bayesian methods [38,42-45], Monte Carlo algorithms [46-48], genetic algorithms [49,50], and regression methods [35,37,39,51-56] have been developed. The numerical method, used in this paper to solve the distribution function, makes use of a discretization of the integral term:

$$
\mathrm{Z}_{\mathrm{DRT}}(\omega)=\sum_{k=1}^{n} \frac{h_{k}}{1+\mathrm{j} \omega \tau_{k}}=R_{\mathrm{p}} \cdot \sum_{k=1}^{n} \frac{g_{k}}{1+\mathrm{j} \omega \tau_{k}} .
$$

If the number of integration steps is set to one, the impedance description of an RC element is obtained:

$$
Z_{\mathrm{RC}}(\omega)=\frac{R}{1+j \omega \tau_{\mathrm{RC}}},
$$

where $\tau=R C=\frac{1}{\omega}$ and $g_{k}=\frac{R}{R_{\mathrm{P}}}$. If the impedance data represents exactly one RC element, then with $n=1$ the Equation (3) would be well defined and the distribution function would be a peak at a fixed time constant. For $n=2$ it can be recognized that the Equation (3) is ill-posed, since both the first and the second RC element would be able to map a perfect semicircle. Thus, the number of iteration steps $\left[\tau_{1}, \ldots, \tau_{n}\right]$ has a critical influence on the quality of the distribution function (illustrated in Figure A1). As long as the interval is identical to the number of measuring points, it is guaranteed that for each measuring point an RC element with corresponding threshold frequency exists. Since the DRT is ohmic-capacitive, no inductive components can be considered and it is assumed:

$$
\Im\{Z(\omega)\} \stackrel{!}{\leq} 0 \quad \forall \omega .
$$

Thus, there is a limited range for the applicability of the DRT to the impedance data as shown in Figure 2. An approach to consider also inductive elements was presented by Danzer adding an ohmic-inductive term to the DRT [37]. Nevertheless, by a boundary analysis, the imaginary part of an RC elements normally follows:

$$
\begin{aligned}
& \lim _{\omega \rightarrow 0} \Im\{Z(\omega)\} \stackrel{! !}{=} 0, \\
& \lim _{\omega \rightarrow \infty} \Im\{Z(\omega)\} \stackrel{!}{=} 0 .
\end{aligned}
$$

For example, if the measurement does not converge against the real axis due to a dominant diffusion process at low frequencies as shown in Figure 2, the associated RC elements can become very large and thus overshadows the entire DRT (see Figure $3 b$ ). 


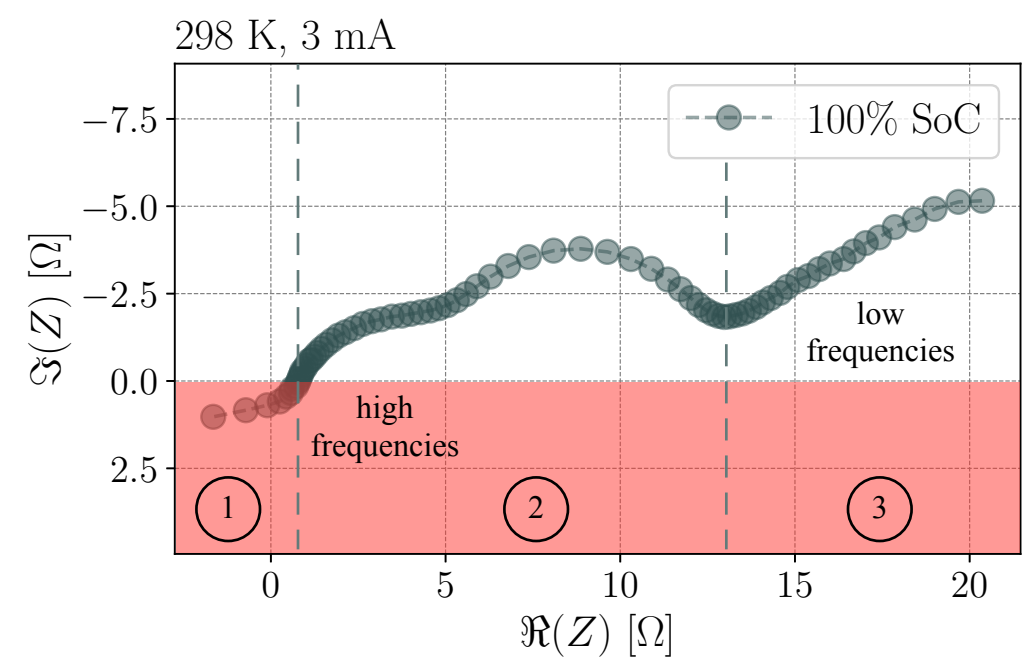

Figure 2. EIS measurement of a ZAB at $298 \mathrm{~K}$ and SoC of $100 \%$. The red marked area shows the transition to the inductive parts which is not considered by default (1), (2) is the area that can be described well via the DRT, and (3) represents a sensitive area.

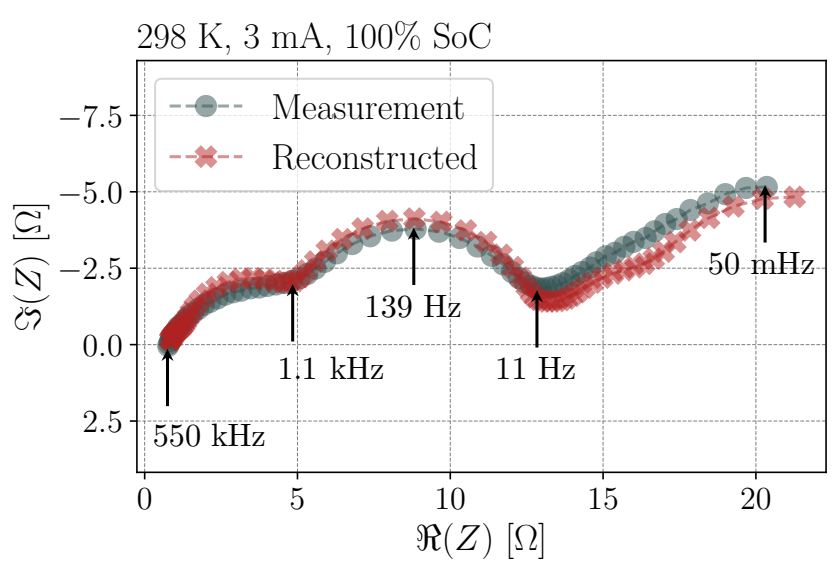

(a) EIS and simulation

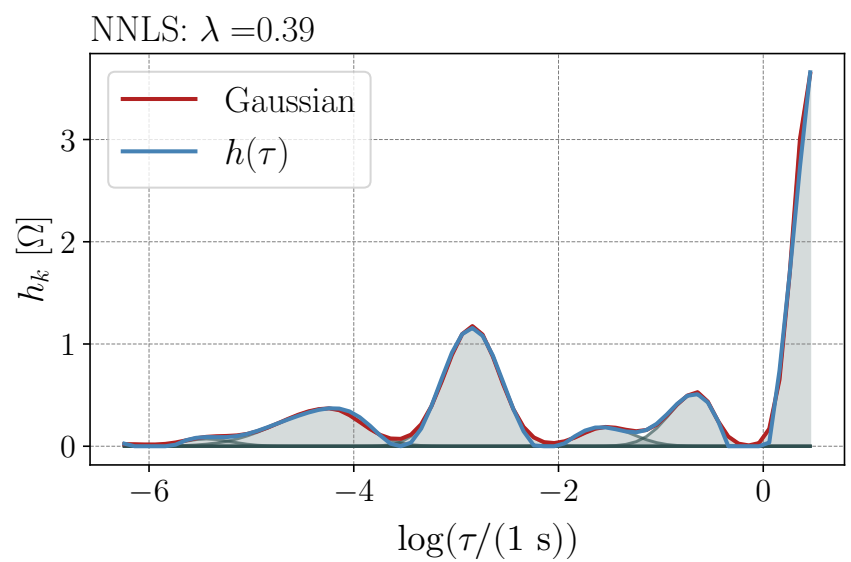

(b) DRT and post-processing

Figure 3. Problem of a not converging EIS measurement at low frequencies. The main peak in the DRT (b) is attributable to the diffusion part, which leads to higher regularization parameters and thus larger deviations (a) in the reconstruction.

Hahn et al. propose to extend the interval of the specified time constants beyond the limits of the measurement frequencies, which is usually given by $\tau_{\min }=\frac{1}{2 \pi f_{\max }}$ to $\tau_{\max }=\frac{1}{2 \pi f_{\min }}$ [35]. It is also possible to exclude the diffusion part from the consideration of the DRT and analyze it through other methods [57]. Figure A2 validates the practicality for extending the time constants for low frequencies as well as for excluding the diffusion part. Finally, the DRT can be seen as a minimization problem between measurement $Z_{\text {Meas }}$ and $Z_{\mathrm{DRT}}$ (cf. Equation (3)):

$$
\min \left\{\left\|Z_{\text {Meas }}-Z_{\text {DRT }}\right\|_{2}^{2}\right\} \text {. }
$$

To solve this problem, only the non-negative least squares (NNLS) [58] and the complex non-linear least squares algorithm (CNLS) [59] are mentioned in the literature. In this study, other existing algorithms with boundary conditions (Powell, TNC, SLSQP, L-BFGS-B) from the Optimization Toolbox of SciPy were evaluated (depicted in Figure 4), with the result that only the NNLS, the sequential least squares programming algorithm (SLSQP) [60], 
which is a slight modification of the NNLS algorithm, and the L-BFGS-B algorithm [61] provide feasible results.
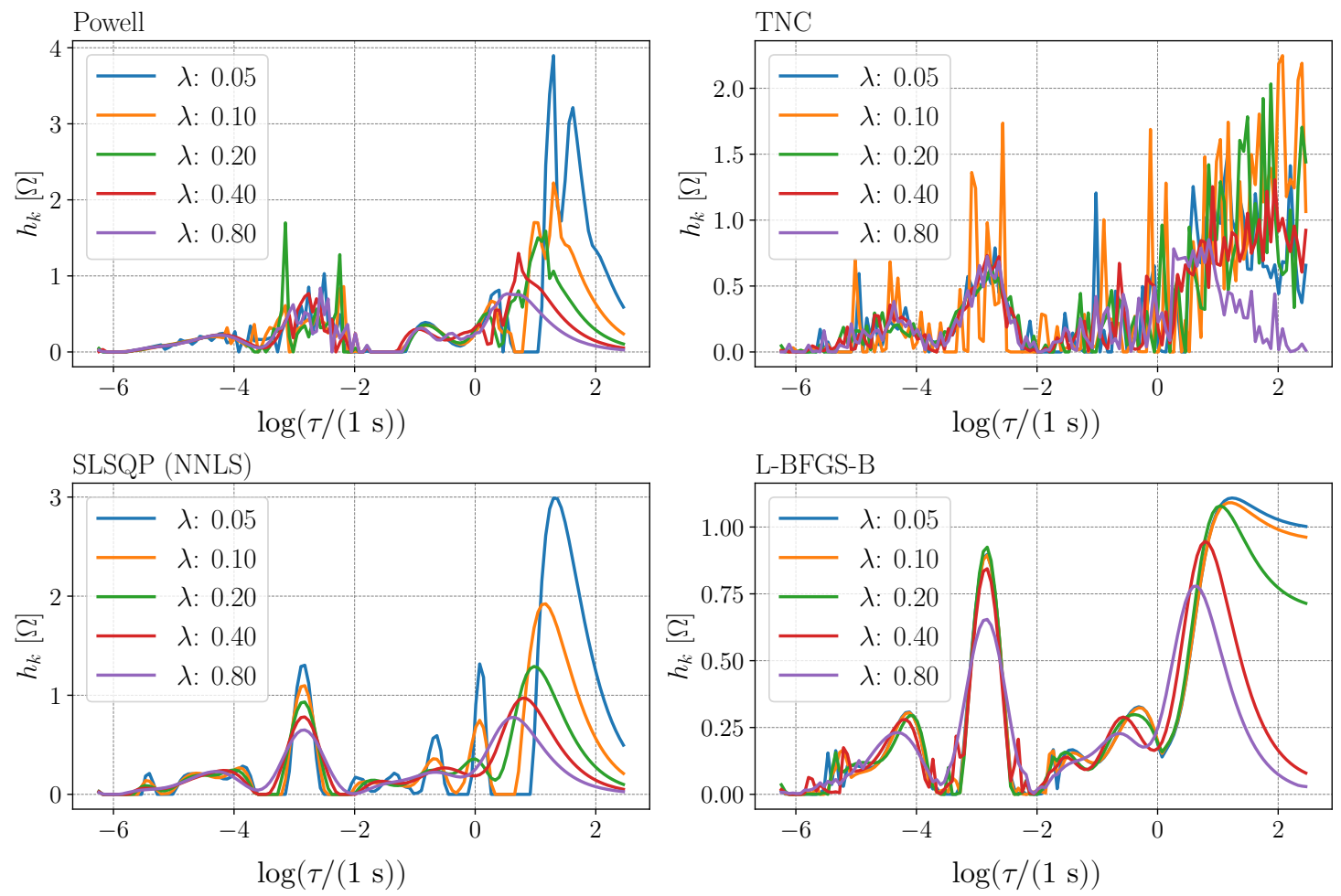

Figure 4. Comparison of different minimization algorithms: Powell, TNC, SLSQP, and L-BFGS-B. The SLSQP algorithm shows the same result as the NNLS algorithm. The regularization parameter $\lambda$ influences the DRT (see Equation (12)) with increasing values and smooths the peaks.

Therefore, the following equations refer only to the NNLS algorithm to ensure comparability within the literature. The NNLS algorithm solves the problem by matrix and vector operations. The Equation (3) becomes a normalized matrix entry:

$$
A_{i, k}=\frac{1}{1+\mathrm{j} \omega_{i} \tau_{k}}
$$

with $\{i \in \mathbb{N} \mid 0<i \leq m\}$ and $\{k \in \mathbb{N} \mid 0<k \leq n\}$. The measurement data is defined as a vector $\boldsymbol{b}$ with $m$ measurement points. Since the measured values are given as complex numbers, which is not supported by the NNLS algorithm, the DRT can be calculated from the real and the imaginary part:

$$
\boldsymbol{A}=\left[\begin{array}{ccc}
\Re\left\{A_{1,1}\right\} & \cdots & \Re\left\{A_{1, n}\right\} \\
\vdots & \ddots & \vdots \\
\Re\left\{A_{m, 1}\right\} & \cdots & \Re\left\{A_{m, n}\right\} \\
\Im\left\{A_{1,1}\right\} & \cdots & \Im\left\{A_{1, n}\right\} \\
\vdots & \ddots & \vdots \\
\Im\left\{A_{m, 1}\right\} & \cdots & \Im\left\{A_{m, n}\right\}
\end{array}\right], \quad \boldsymbol{b}=\left[\begin{array}{c}
\Re\left\{Z_{\text {Meas }, 1}\right\} \\
\vdots \\
\Re\left\{Z_{\text {Meas }, m}\right\} \\
\Im\left\{Z_{\text {Meas }, 1}\right\} \\
\vdots \\
\Im\left\{Z_{\text {Meas }, m}\right\}
\end{array}\right] .
$$

The distribution function is also specified as a vector $x$ with the constraint:

$$
x_{k}=g_{k} \geq 0 \quad \forall k \in \mathbb{N} \mid 0<k \leq n .
$$


In the case that the solution of the minimization problem is an ill-posed problem, since the data may be noisy or the sampling frequency is higher than the measurement frequency, a regularization term according to Tikhonov et al. can be added to the Equation (8) in matrix notation [62]:

$$
\min \left\{\|\boldsymbol{A} \boldsymbol{x}-\boldsymbol{b}\|_{2}^{2}+\lambda_{\mathrm{DRT}}\|\boldsymbol{M} \boldsymbol{x}\|_{2}^{2}\right\}
$$

If the regularization matrix is simplified by the identity matrix, the ridge regression with the regularization parameter $\lambda_{\mathrm{DRT}}$ is obtained.

\subsection{Determination of the Regularization Parameter}

The determination of the regularization parameter for the ridge regression is the current state of research and leads to different approaches $[39,51,55,63]$. Without regularization, the DRT would tend to oscillate, but excessive values for $\lambda$ can suppress characteristic peaks (see Figure 4). Hahn et al. have examined the common methods (Discrepancy, Cross-Validation, and L-Curve) and have found them to be unsatisfactory [35]. They have proposed the solution using the residual sum of squares as a quality parameter. Based on this idea, a modified approach was used here that uses the Nelder-Mead method to optimize the regularization parameter so that the error between measurement and reconstructed spectrum of DRT after post-processing (see Section 2.4) becomes minimal:

$$
\min \left\{\frac{1}{m} \sum_{i=1}^{m}\left|Z_{\mathrm{Meas}, i}-Z_{\mathrm{DRT}, i}\left(\lambda_{\mathrm{DRT}}\right)\right|\right\}
$$

Since this approach quickly converges to a local minimum and thus the determination of the parameter strongly depends on the initial condition, the regularization parameter was estimated via a brute-force algorithm by variation of $\left\{\lambda_{\mathrm{DRT}} \in \mathbb{R} \mid 0 \leq \lambda_{\mathrm{DRT}} \leq 1\right\}$ in advance. This method has proven to be very reliable for reconstruction of the measured impedance data.

\subsection{Preparation of DRT for Electrochemical Analysis}

With only the determination of $h_{k}$, it is possible to identify the number of chemicalphysical processes and to observe the change of the DRT, e.g., via charging and discharging or aging [64]. However, quantitative statements about the individual processes are not feasible. Since the DRT already represents the sum of RC elements, it is obvious to describe the processes by an equivalent circuit based on RC elements, provided that the system is well known, in order to reasonably limit the number of RC elements [65]. Moreover, not every process can be described by a limited number of RC elements [65]. Another idea is to consider the DRT not as a sum of RC elements, but as a function, which in turn can be approximated by arbitrary functions depending on physical processes [30]. The superposition of these processes, on the other hand, maps the DRT:

$$
g_{\mathrm{DRT}}(\tau)=\sum_{j=1}^{N} g_{\text {Peak }, j}(\tau)
$$

Since the solution of the DRT already provides a broad distribution of the relaxation times, it is obvious to describe the individual processes by a Gaussian probability distribution function $[35,41,44,49,50]$ :

$$
g_{\text {Peak }, j}=a_{0, j} \cdot \exp \left\{-\frac{1}{2}\left(\frac{\log _{10}\left(\tau / \tau_{\mathrm{p}, j}\right) \cdot\left(1+s_{j} \cdot \operatorname{sgn}\left(\log _{10}\left(\tau / \tau_{\mathrm{p}, j}\right)\right)\right.}{\sigma_{j}}\right)^{2}\right\}
$$

The modified Gaussian distribution, here, includes the prefactor $a_{0, j}$, which adjusts the height of the Gaussian curve at the expected value $\tau_{\mathrm{p}, j}$. The variance $\sigma_{j}^{2}$ determines the width of the probability distribution function and the skewness $s_{j}$ describes the asymmetry. 
Wide or skewed distributions could indicate non-ideal processes, inhomogeneities, side reactions, or errors in the measurement.

\section{Results}

\subsection{Regularization}

The determination of the regularization parameter $\lambda$, using the proposed routine, was performed for each measured data set. The results are shown in Figure 5. It was demonstrated that, depending on the SoC, the temperature and the currents used, large deviations arose in the determination of a suitable regularization parameter. Especially at the higher temperatures, the range for $\lambda$ extended from about 0.05 to 0.7 , while the median of all data sets varied between approximately 0.05 and 0.2. Besides the already discussed number of time constants and the extension of the time domain, large deviation occurred due to the strong change of the impedance spectra between $100 \%$ SoC and $90 \%$ SoC on the one hand and on the other hand to the erroneous approximation of the diffusion part by a limited number of RC elements. Figure A3 shows the comparison between an optimal $(\lambda=0.246)$, a lower $(\lambda=0.1)$ and a higher $(\lambda=0.4)$ regularization parameter for the measured impedance spectrum at $294 \mathrm{~K}$ and $100 \%$ SoC. Lower values lead to more peaks and correspondingly to additional RC elements, which in principle improves the reconstruction of the measurement; however, the physical interpretation of the DRT becomes more and more impossible. Higher values smooth out smaller peaks, resulting in fewer RC elements, greatly simplifying the reconstruction and possibly leaving small hidden processes in the DRT undetected. Thus, the most significant discrepancy in finding an appropriate regularization parameter is less the method and more the result for interpreting the data. According to the high deviation and the associated change in DRT as well as the physical significance, the variation of the regularization parameter within a technology is not meaningful. Consequently, for all further investigations, the upper median of $\lambda=0.2$ was set for this parameter.

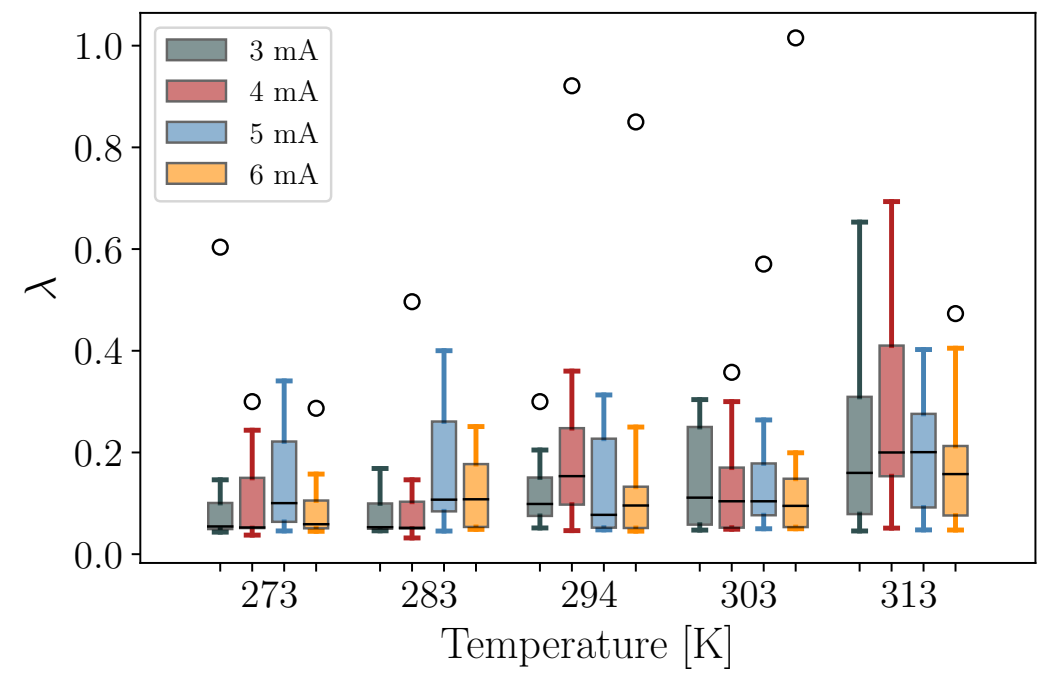

Figure 5. Calculation of the regularization parameter $\lambda$ depending on the temperatures between $273 \mathrm{~K}$ and $313 \mathrm{~K}$ as well as on the currents $3 \mathrm{~mA}$ to $6 \mathrm{~mA}$. A boxplot represents the calculation of $\lambda$ at each measured SoC. The black line within the box indicates the median and the circles show outliers.

\subsection{Temperatures and Currents}

The discharge profiles at different currents, i.e., between $2 \mathrm{~mA}$ and $10 \mathrm{~mA}$, are shown in Figure 6. The investigated cells had a diameter of $7.8 \mathrm{~mm}$, resulting in current densities of about $42 \mathrm{Am}^{-2}$ to $210 \mathrm{Am}^{-2}$. The voltage profiles and the capacities were diminished with increasing discharge currents. Four different operating phases could be identified through the analysis of the discharge profiles related to the applied currents: 
I As shown in Figure 1, the initial operating phase could be subdivided into three specific processes. The process I.1 was very fast and has slightly recovered the voltage in respect of the initial voltage drop. This was followed by process I.2, which resulted in a linear decrease of the voltage until a minimum was reached. In process I.3 the voltage gradually recovered and converged to a constant value. All three processes occurred independently of the current, with process I.1 and I.2 also appearing to be time independent.

II The corresponding capacity in the nearly constant voltage operating phase II was depended on the the applied discharge currents, i.e., the greater the discharge current, the smaller the duration.

III After the constant operating phase for currents greater than $4 \mathrm{~mA}$, an additional voltage drop was observable. Especially between $4 \mathrm{~mA}$ and $8 \mathrm{~mA}$ this phase is clearly detectable.

IV In the final operating phase, the voltage decreased rapidly until it reached the cut-off voltage. As the current increased, the boundary between phase III and IV became unclear.

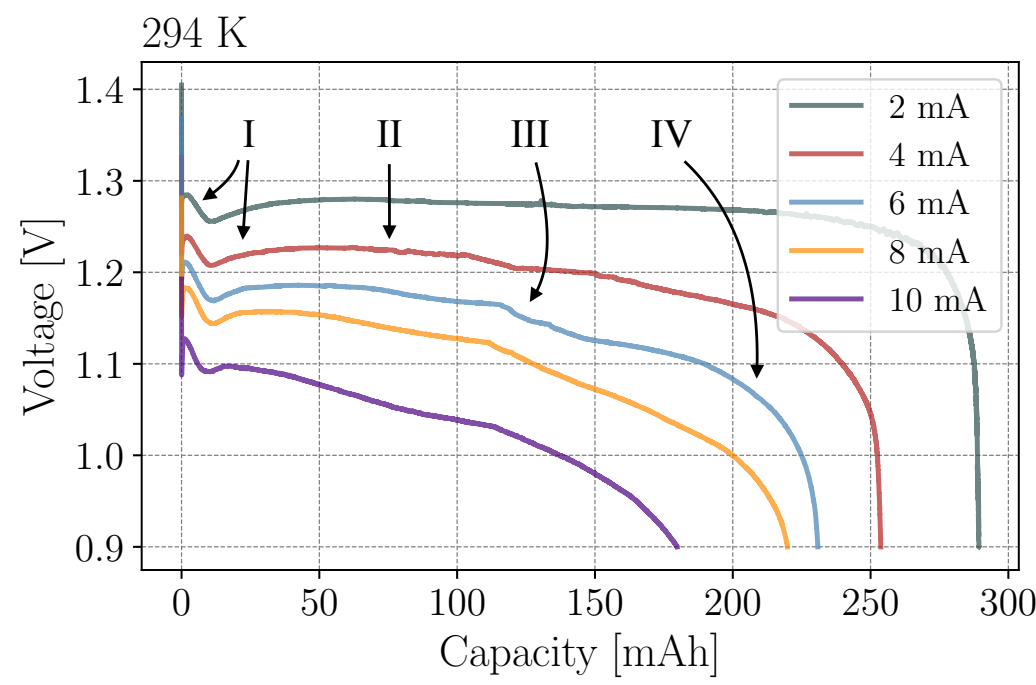

Figure 6. ZAB PR48 discharge profiles at $294 \mathrm{~K}$ and various constant discharge currents from $2 \mathrm{~mA}$ to $10 \mathrm{~mA}$. The annotations I-IV represent different operating phases of the cell.

Figure 6 shows a strong dependence of the discharge capacity on the applied discharge currents. The capacities were measured as a function of current and temperature in order to target the corresponding SoC values, and are presented in Table 1 . The values indicate that the maximum available capacity was diminished by both high currents and low temperatures. Especially at currents higher than $3 \mathrm{~mA}$ and temperatures below $273 \mathrm{~K}$, it was not possible to determine the capacity via a constant current discharge. The dependence of the temperature is depicted in Figure A4.

Table 1. Measured capacities depending on discharge current and ambient temperature.

\begin{tabular}{cccccccc}
\hline Current & $\mathbf{2 5 3} \mathbf{K}$ & $\mathbf{2 6 3} \mathbf{K}$ & $\mathbf{2 7 3} \mathbf{K}$ & $\mathbf{2 8 3} \mathbf{K}$ & $\mathbf{2 9 4} \mathbf{K}$ & $\mathbf{3 0 3} \mathbf{K}$ & $\mathbf{3 1 3} \mathbf{K}$ \\
\hline $3 \mathrm{~mA}$ & $39 \mathrm{mAh}$ & $43 \mathrm{mAh}$ & $202 \mathrm{mAh}$ & $257 \mathrm{mAh}$ & $254 \mathrm{mAh}$ & $275 \mathrm{mAh}$ & $287 \mathrm{mAh}$ \\
$4 \mathrm{~mA}$ & - & - & $188 \mathrm{mAh}$ & $231 \mathrm{mAh}$ & $232 \mathrm{mAh}$ & $246 \mathrm{mAh}$ & $287 \mathrm{mAh}$ \\
$5 \mathrm{~mA}$ & - & - & $108 \mathrm{mAh}$ & $211 \mathrm{mAh}$ & $221 \mathrm{mAh}$ & $239 \mathrm{mAh}$ & $261 \mathrm{mAh}$ \\
$6 \mathrm{~mA}$ & - & - & $89 \mathrm{mAh}$ & $187 \mathrm{mAh}$ & $215 \mathrm{mAh}$ & $220 \mathrm{mAh}$ & $260 \mathrm{mAh}$ \\
\hline
\end{tabular}




\subsection{Process Analysis}

The DRT is intended for identifying and quantifying chemical-physical processes from impedance data without extensive model fitting. For the proof of concept of the DRT, the data set at $303 \mathrm{~K}$ was selected because it yielded the smallest variation in the mean value of the regularization parameter with respect to the current. With a regularization parameter of $\lambda=0.2$, eight peaks were found for all currents at an SoC of $100 \%$ (see Figure $7 \mathrm{a}$, cf. Figure A2b). The corresponding time constant $\tau_{0}$ from Table 2 is an artifact that arose from the measurement, since it was not guaranteed that the truncated spectrum ended at the condition $\Im\left\{Z\left(\omega_{0}\right)\right\}=0$. The SoC values in Figure 7 represent the desired SoCs, which slightly differed between the measurements, as shown in Table 2 . However, two main processes, at an SoC of $100 \%$, were identified at $\tau_{4}$ and at $\tau_{8}$ with $h_{4}=0.834 \Omega$ and $h_{8}=1.355 \Omega$, respectively. The time constants $\tau_{2}$ and $\tau_{3}$ as well as $\tau_{6}$ and $\tau_{7}$ were strongly dependent on the regularization parameter and were already merged as one peak at a value of $\lambda=0.3$ resulting in six processes. At an SoC of about $90 \%$ the main process $\tau_{4}$ and the process $\tau_{3}$ disappeared. Furthermore, the three processes $\tau_{5}$ to $\tau_{7}$ formed two processes, but it was not possible to distinguish exactly which peak have merged. The process $\tau_{6}$ showed a remarkable dependence on the current. The process was reduced with increasing currents and have slightly migrated at an SoC of approximately $50 \%$ into the process $\tau_{8}$ for the currents $5 \mathrm{~mA}$ and $6 \mathrm{~mA}$. For the currents $3 \mathrm{~mA}$ and $4 \mathrm{~mA}$, this effect also occurred, but only at an SoC of about $20 \%$. In general, the resistance of the process grew with decreasing SoC until it entered the process $\tau_{8}$. The last process $\tau_{8}$ was relatively unaffected by the current and started to increase significantly in resistance at about $20 \%$ SoC.

Table 2. Time constants and height of the characteristic peaks depending on the SoC at $303 \mathrm{~K}$ and a discharge current of $3 \mathrm{~mA}$.

\begin{tabular}{|c|c|c|c|c|c|c|c|c|c|}
\hline SoC in $\%$ & $\log \left(\tau_{0}\right)$ & $\log \left(\tau_{1}\right)$ & $\log \left(\tau_{2}\right)$ & $\log \left(\tau_{3}\right)$ & $\log \left(\tau_{4}\right)$ & $\log \left(\tau_{5}\right)$ & $\log \left(\tau_{6}\right)$ & $\log \left(\tau_{7}\right)$ & $\log \left(\tau_{8}\right)$ \\
\hline 100 & $4.6 \times 10^{-7}$ & $2.5 \times 10^{-6}$ & $1.9 \times 10^{-5}$ & $9.8 \times 10^{-5}$ & $1.2 \times 10^{-3}$ & $1.7 \times 10^{-2}$ & $1.6 \times 10^{-1}$ & $9.2 \times 10^{-1}$ & 9.7 \\
\hline 90.2 & $4.6 \times 10^{-7}$ & $3.1 \times 10^{-6}$ & $2.5 \times 10^{-5}$ & - & - & $9.2 \times 10^{-3}$ & $1.3 \times 10^{-1}$ & - & 3.4 \\
\hline 80.3 & $4.6 \times 10^{-7}$ & $3.1 \times 10^{-6}$ & $2.1 \times 10^{-5}$ & - & - & $1.2 \times 10^{-2}$ & $1.5 \times 10^{-1}$ & - & 3.4 \\
\hline 70.5 & $4.6 \times 10^{-7}$ & $3.1 \times 10^{-6}$ & $2.5 \times 10^{-5}$ & - & - & $1.4 \times 10^{-2}$ & $1.5 \times 10^{-1}$ & - & 3.4 \\
\hline 60.7 & $4.6 \times 10^{-7}$ & $2.7 \times 10^{-6}$ & $1.8 \times 10^{-5}$ & $3.5 \times 10^{-4}$ & - & $1.7 \times 10^{-2}$ & $1.5 \times 10^{-1}$ & - & 4.6 \\
\hline 50.5 & $4.6 \times 10^{-7}$ & $2.7 \times 10^{-6}$ & $1.6 \times 10^{-5}$ & $3.1 \times 10^{-4}$ & - & $1.7 \times 10^{-2}$ & $1.8 \times 10^{-1}$ & - & 5.3 \\
\hline 41.0 & $4.6 \times 10^{-7}$ & $2.7 \times 10^{-6}$ & $1.6 \times 10^{-5}$ & - & - & $2.2 \times 10^{-2}$ & $2.0 \times 10^{-1}$ & - & 5.3 \\
\hline 31.1 & $4.6 \times 10^{-7}$ & $2.7 \times 10^{-6}$ & $1.6 \times 10^{-5}$ & $2.0 \times 10^{-4}$ & - & - & $3.7 \times 10^{-1}$ & - & 4.6 \\
\hline 21.3 & $4.6 \times 10^{-7}$ & $2.7 \times 10^{-6}$ & $1.6 \times 10^{-5}$ & $1.1 \times 10^{-4}$ & - & - & - & - & 4.6 \\
\hline 11.5 & $4.6 \times 10^{-7}$ & $3.1 \times 10^{-6}$ & $1.8 \times 10^{-5}$ & $2.3 \times 10^{-4}$ & - & - & $1.8 \times 10^{-1}$ & - & 2.5 \\
\hline 1.6 & $4.6 \times 10^{-7}$ & $3.6 \times 10^{-6}$ & $2.5 \times 10^{-5}$ & - & - & $1.4 \times 10^{-2}$ & $9.8 \times 10^{-2}$ & $3.7 \times 10^{-1}$ & 4.6 \\
\hline SoC in $\%$ & $h_{0}$ in $\Omega$ & $h_{1}$ in $\Omega$ & $h_{2}$ in $\Omega$ & $h_{3}$ in $\Omega$ & $h_{4}$ in $\Omega$ & $h_{5}$ in $\Omega$ & $h_{6}$ in $\Omega$ & $h_{7}$ in $\Omega$ & $h_{8}$ in $\Omega$ \\
\hline 100 & 0.081 & 0.061 & 0.151 & 0.201 & 0.834 & 0.135 & 0.247 & 0.311 & 1.355 \\
\hline 90.2 & 0.057 & 0.051 & 0.137 & - & - & 0.095 & 0.374 & - & 0.893 \\
\hline 80.3 & 0.029 & 0.057 & 0.134 & - & - & 0.106 & 0.497 & - & 0.931 \\
\hline 70.5 & 0.042 & 0.055 & 0.139 & - & - & 0.125 & 0.549 & - & 0.954 \\
\hline 60.7 & 0.071 & 0.080 & 0.124 & 0.039 & - & 0.153 & 0.581 & - & 0.894 \\
\hline 50.5 & 0.080 & 0.081 & 0.116 & 0.038 & - & 0.154 & 0.601 & - & 0.912 \\
\hline 41.0 & 0.089 & 0.076 & 0.111 & - & - & 0.168 & 0.639 & - & 0.944 \\
\hline 31.1 & 0.072 & 0.074 & 0.103 & 0.031 & - & - & 0.665 & - & 0.988 \\
\hline 21.3 & 0.048 & 0.072 & 0.106 & 0.035 & - & - & - & - & 1.079 \\
\hline 11.5 & 0.033 & 0.051 & 0.115 & 0.030 & - & - & 0.343 & - & 2.317 \\
\hline 1.6 & 0.030 & 0.042 & 0.127 & - & - & 0.097 & 0.256 & 0.382 & 3.039 \\
\hline
\end{tabular}




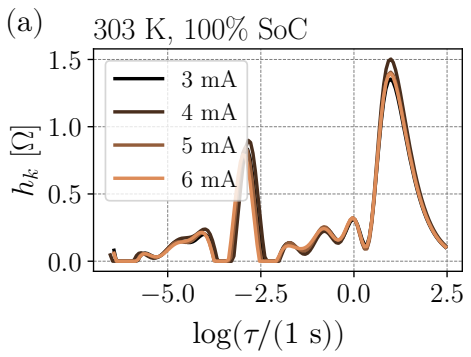

(d)

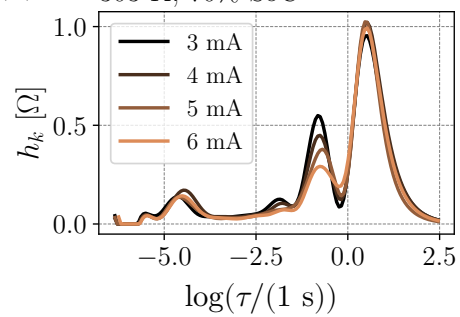

(g)

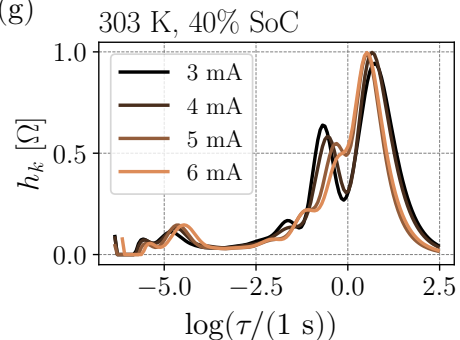

(j) $303 \mathrm{~K}, 10 \% \mathrm{SoC}$

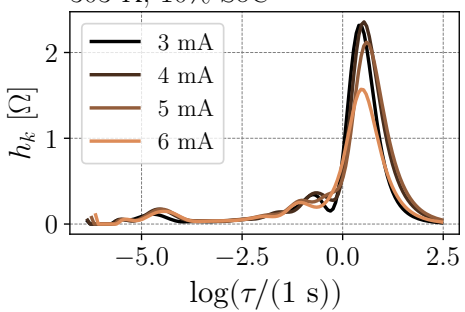

(b)

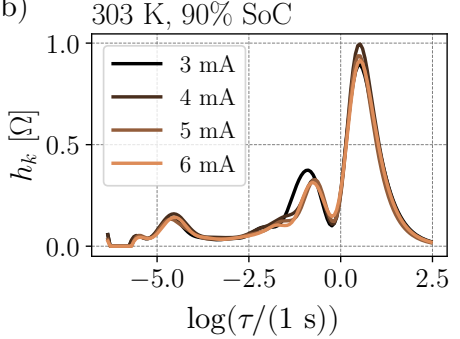

(e)

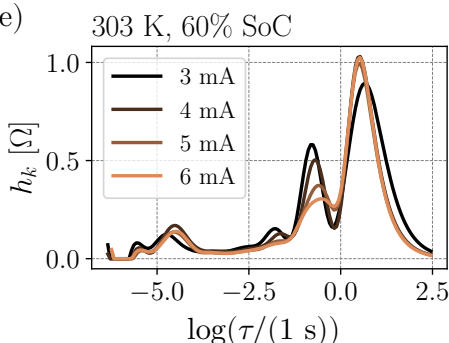

(h)

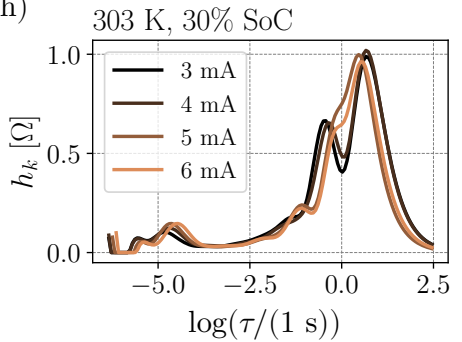

(k) $303 \mathrm{~K}, 0 \% \mathrm{SoC}$

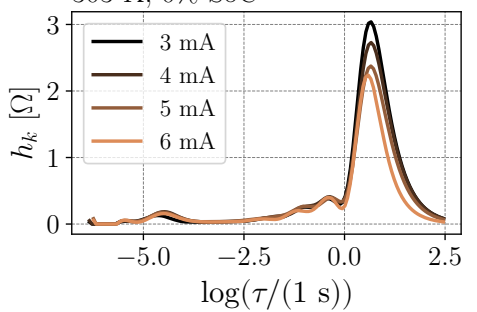

(c)

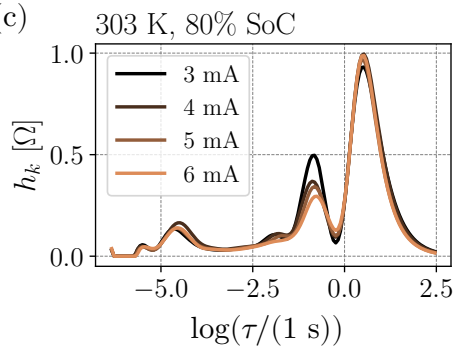

(f)

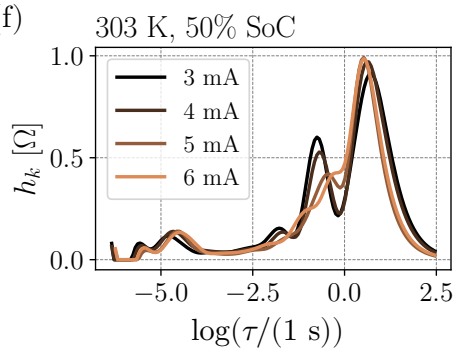

(i)

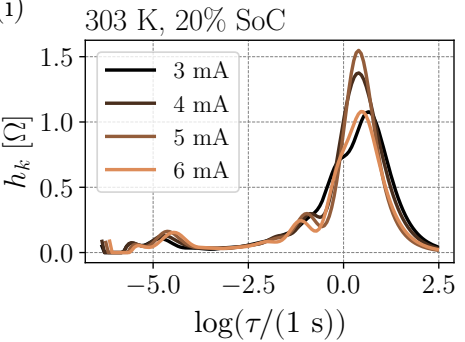

Figure 7. Process analysis of a ZAB at $303 \mathrm{~K}$ via the DRT related to different currents and SoCs.

The DRT in Figure 7a and the discharge curves in Figure 6 revealed a very inhomogeneous operating phase, i.e., operating phase I, during the first $10 \%$ SoC discharge. The measurement routine, depicted in Figure 1, was not suitable for monitoring this phase because the measurement steps were too large. Therefore, a loop of EIS measurement was performed and the cell was discharged with a superimposed discharge current during the EIS measurement. The corresponding EIS measurements during the first $1 \%$ discharge are shown in Figure 8a. Two semicircles and the beginning of the diffusion part were identified for $100 \%$ SoC. The second semicircle disappeared for decreasing SoCs. The ECM represents two main processes with each process having a distribution of time constants considered by the constant phase elements (CPE) [66]. Such a construct is a simple method for fitting the impedance data, but without a physical meaning at first [30]. The fit of the ECM related to the EIS measurement at $100 \%$ SoC is illustrated in Figure $8 \mathrm{c}$ and at 98.76\% SoC in Figure 8d. The corresponding values of the ECM are provided in Table A1. The mean squared error between the simulation and the measurement increased with the disappearance of the second semicircle. The standard fitting procedure could not decide which of the two semicircles disappeared and in which direction the semicircle drifted. The associated DRT in Figure 9a, on the other hand, showed a clear trend. The process at $\log (\tau) \approx-3$ in Figure $9 a$, which is related to the second semicircle in Figure 8a, was slightly shifted towards $\log (\tau) \approx-4$ and the amplitude was logarithmically decreased 
during discharge until the process disappeared. While this process was decaying, a new process appeared at $\log (\tau) \approx-2.5$ (see Figure $9 \mathrm{c}$ ), first steadily increasing to about $5 \%$ discharge and then decreasing until a constant value was reached (see Figure 9c). The process at $\log (\tau) \approx-1.5$ decreased in a similar manner to the disappearing process, but stabilized after the first $1 \%$ discharge.

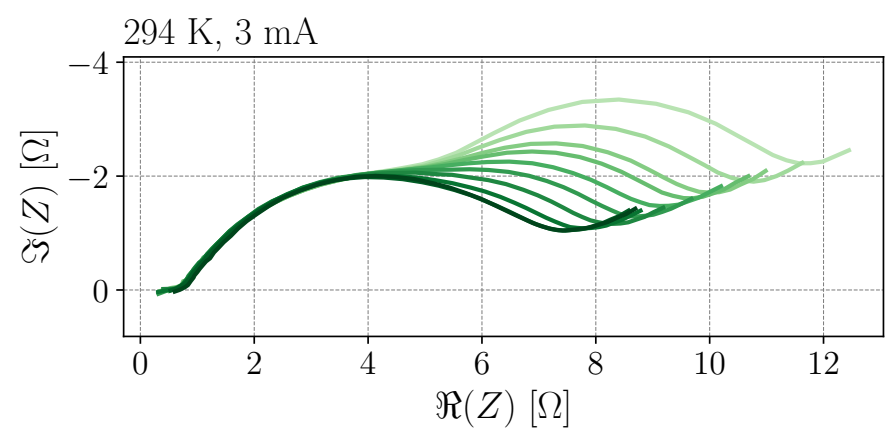

(a) EIS from 100 to $98.76 \%$ SoC

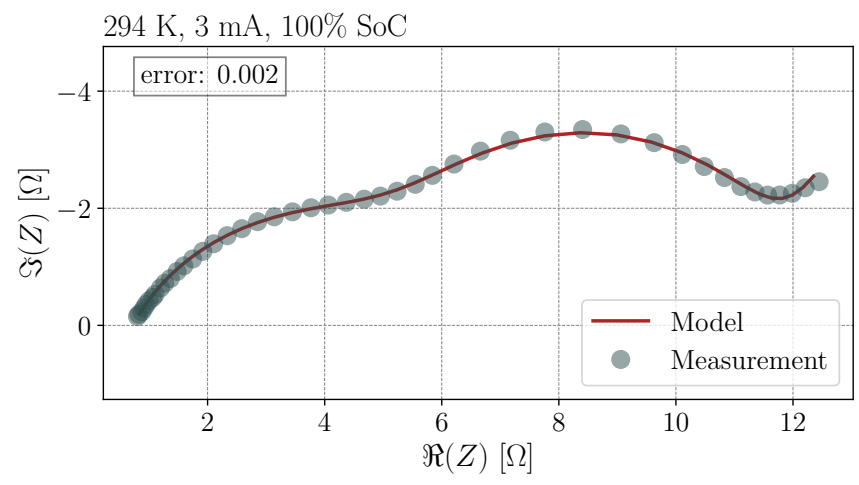

(c) ECM model at $100 \%$ SoC

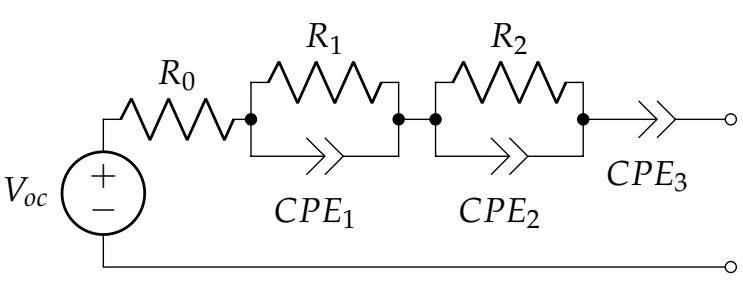

(b) ECM for a ZAB

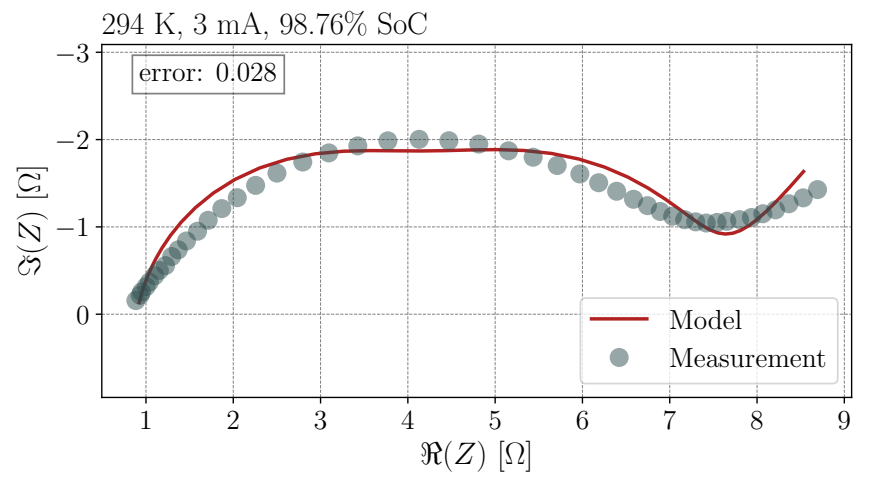

(d) ECM model at $98.76 \%$ SoC

Figure 8. Process analysis of a ZAB at $294 \mathrm{~K}$ and a discharge current of $3 \mathrm{~mA}$. (a) shows the EIS and (b) represents a corresponding equivalent circuit. (c,d) depict the reconstructed EIS from the ECM.

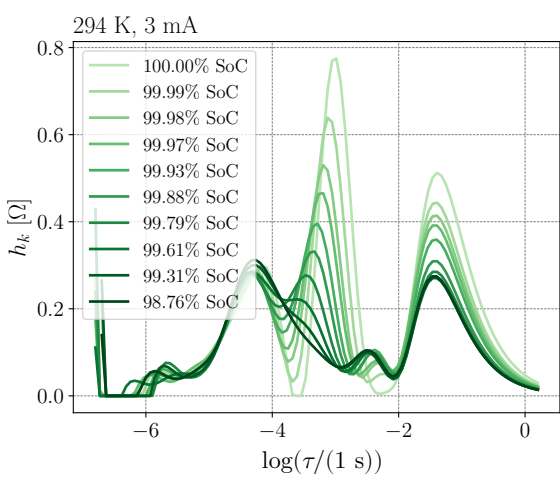

(a) DRT from 100 to $98.76 \%$ SoC

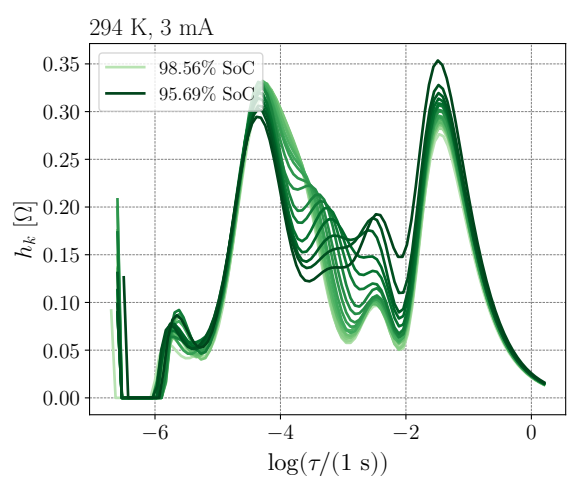

(b) DRT from 98.56 to $95.69 \%$ SoC

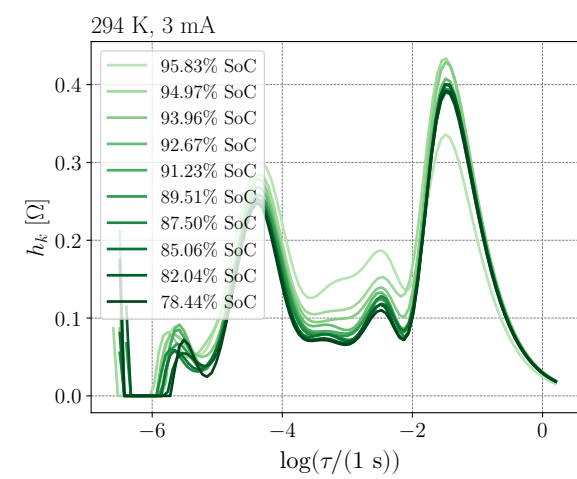

(c) DRT from 95.83 to $78.44 \%$ SoC

Figure 9. Process analysis of the first and second operating phase of a ZAB at $294 \mathrm{~K}$ and a discharge current of $3 \mathrm{~mA}$. $(\mathbf{a}, \mathbf{c})$ represent 10 logarithmically extracted values from the data set, respectively, and (b) depicts 20 linear SOC steps in a range from $98.56 \%$ to $95.69 \%$ SoC. 
Figure 10 shows that the DRT could also be used for the quantification of operating phase III. Comparing the discharge curves from Figure 6, this phase was not detectable at low currents, which the DRT in Figure 10a reflects. Already, at a discharge current of $4 \mathrm{~mA}$, the process at $\log (\tau) \approx-0.5$ was gradually merging with the process at $\log (\tau) \approx 0.5$ with decreasing SoC. This effect intensified abruptly between $33.9 \%$ and $24.4 \%$ SoC, as shown in Figure 10c. The end of operating phase IV was also clearly visible in the DRT, evidenced by a sudden increase in resistance at $\log (\tau) \approx 0.5$, illustrated in Figure $10 \mathrm{~b}$.

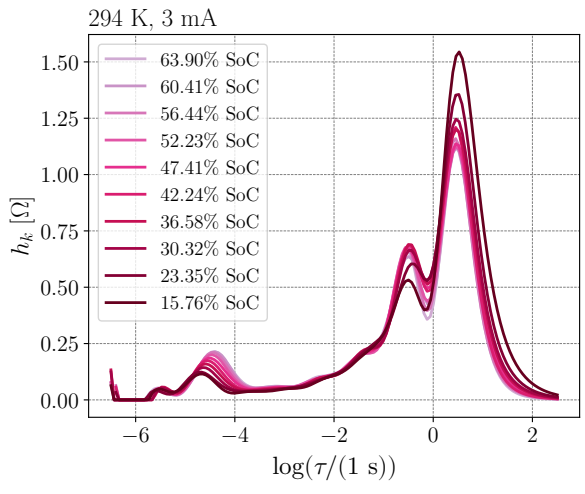

(a) DRT from 63.90 to $15.76 \%$ SoC

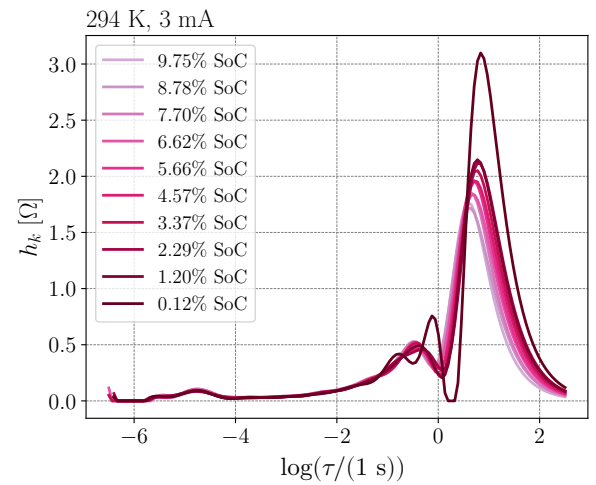

(b) DRT from 9.75 to $0.12 \%$ SoC

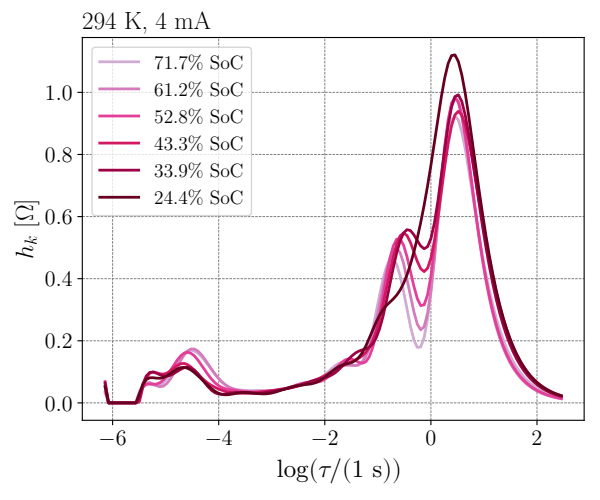

(c) DRT from 71.70 to $24.40 \%$ SoC

Figure 10. Process analysis of a ZAB at $294 \mathrm{~K}$ with $(\mathbf{a}, \mathbf{b})$ at $3 \mathrm{~mA}$ and (c) with $4 \mathrm{~mA}$ discharge current.

The investigated ZABs showed a temperature dependence (cf. Figure A4); however, operating phase I. 1 did not seem to be affected by this dependency. Figure 11 reveals that at all temperatures the process at $\log (\tau) \approx-3$ in operating phase I. 1 appeared. The shape of the DRT differed marginally between the temperatures of $273 \mathrm{~K}$ and $313 \mathrm{~K}$, but the peaks of the two main processes, i.e., $\log (\tau) \approx-3$ and $\log (\tau) \approx-1.5$, showed a higher resistance towards the lower temperatures, as depicted in Figure 11 b,c. With temperatures below $273 \mathrm{~K}$, the process at $\log (\tau) \approx-3$ was tremendously suppressed, showing only half the resistance at $263 \mathrm{~K}$ in comparison to $273 \mathrm{~K}$ (see Figure 11a).

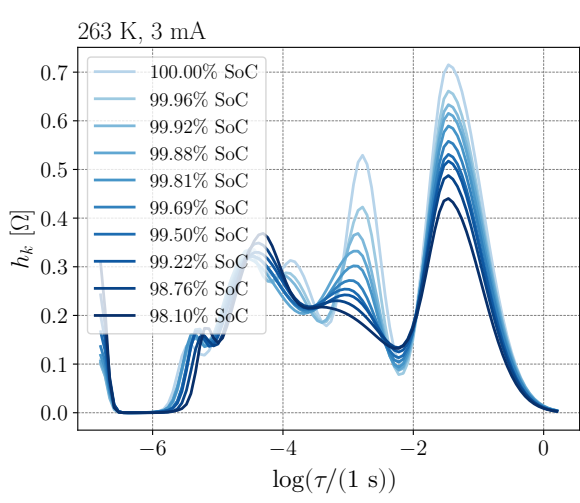

(a) DRT from 100 to $98.10 \%$ SoC

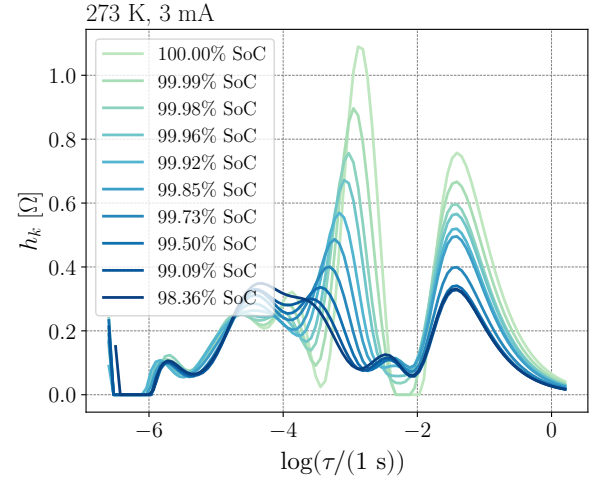

(b) DRT from 100 to $98.36 \% \mathrm{SoC}$

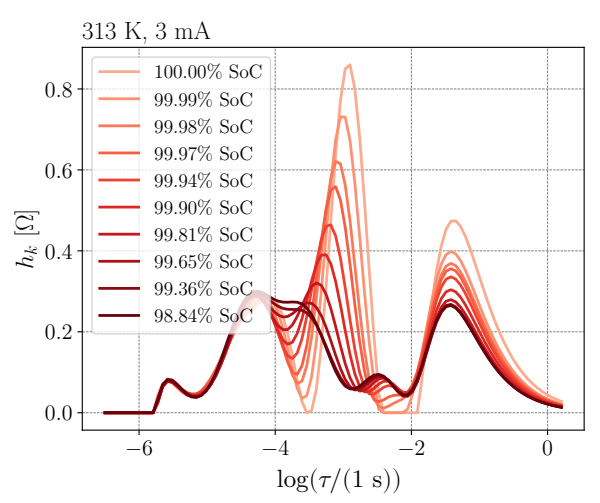

(c) DRT from 100 to $98.84 \% \mathrm{SoC}$

Figure 11. Analysis of operating phase I at different temperatures at $3 \mathrm{~mA}$ discharge current.

The correlation of the temperature of the DRT at a fixed SoC and a discharge current of $3 \mathrm{~mA}$ is shown in Figure 12. The lower the temperatures were, the more significant was the range between $\log (\tau)=-2$ and $\log (\tau)=0$ at an SoC of about $100 \%$ (see Figure 12a). It should be critically mentioned here that in contrast to Figure 11, the full frequency range was used for the measurement, which resulted in longer measurement times and a possible inaccuracy. In the medium State-of-Charge related to Figure $12 \mathrm{~b}$, this range was more prominent for higher temperatures and, at the same time, the resistance at $\log (\tau) \approx 0.5$ decreased. Finally, for higher temperatures from $294 \mathrm{~K}$, the process at $\log (\tau) \approx 0.5$ became 
dominant with decreasing SoC (see Figure 12c). The same process, on the other hand, showed no dependence on SoC at $273 \mathrm{~K}$ and only a minor dependence at $283 \mathrm{~K}$.

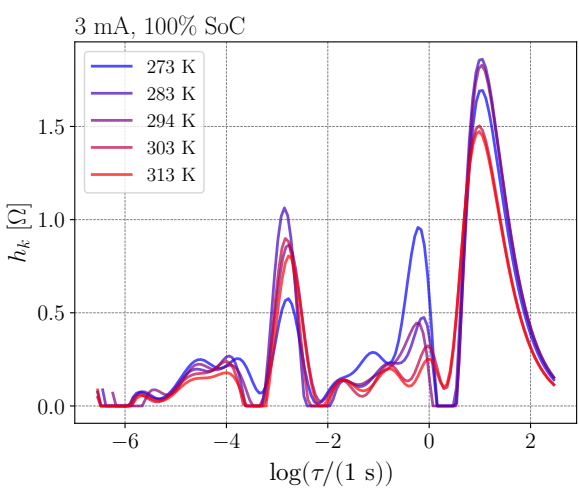

(a) DRT at $100 \% \mathrm{SoC}$

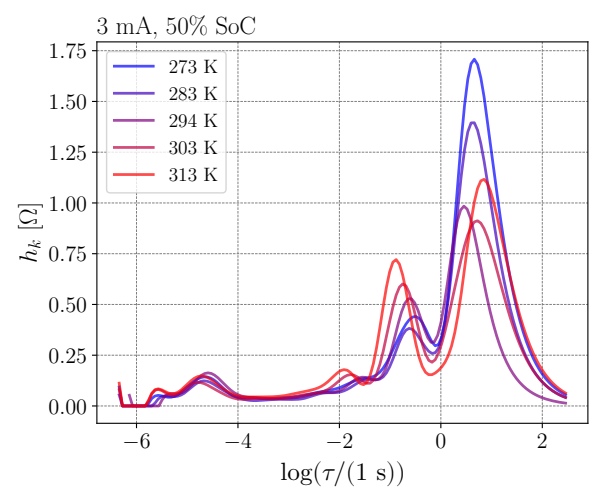

(b) DRT at about $50 \%$ SoC

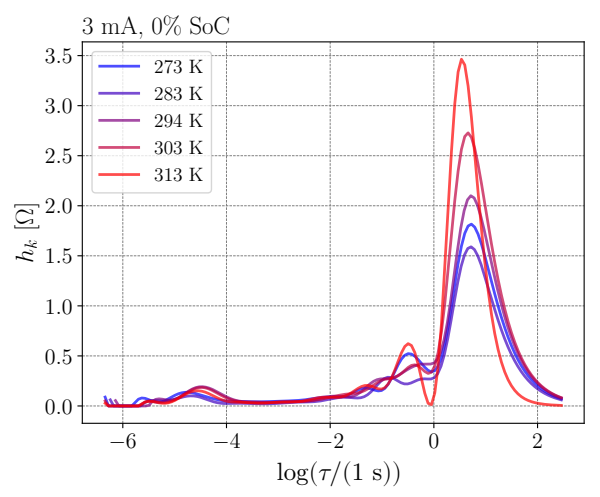

(c) DRT at about $0 \%$ SoC

Figure 12. Influence of temperature at different SoCs and a discharge current of $3 \mathrm{~mA}$.

\section{Discussion}

\subsection{Capacity}

None of the cells tested could reached the manufacturer's specification of $300 \mathrm{mAh}$. This is probably due to the way the capacity was determined. The cells, here, were discharged with a constant discharge current until the cut-off voltage of $0.9 \mathrm{~V}$ was reached. In contrast, the standard [67] defines the determination of the operating life via a constant resistance. This in turn leads to a reduced current when the potential drops, so that the load is reduced towards the cut-off voltage and thus more capacity can be obtained. Ingale et al. have shown that the capacity also depends on the ambient humidity and the capacity was halved in dry air compared to $30 \%$ relative humidity [68]. Different temperatures in the climatic chamber can lead to different humidities and thus the measurements were probably affected by an unknown error. Penteado and Bento have discussed, beside the deviation of the nominal capacity from the measured capacity of different manufacturers, the average service of the PR48 cell type, which showed a variation of $266 \pm 26 \mathrm{~h}$ [69]. These results confirm the capacity measurements in this study that each cell may have a different factory-made capacity. Thus, the determination of the capacity via a separate measurement can only provide valid values for more cells to a limited extent. Therefore, the humidity and the nominal capacity should be critically mentioned in further investigations.

\subsection{Operating Phases}

First, it is important to understand the basic working principle of a ZAB in order to interpret the data obtained from the DRT. The main process is the oxidation of zinc during discharge. This process does not take place immediately and is characterized by at least one more intermediate step. The electrolyte used is usually $30 \%$ potassium hydroxide solution [70], which was also assumed for the cell type studied here. At this concentration, the intermediate step is defined by the formation of zincate $\mathrm{Zn}(\mathrm{OH})_{4}{ }^{2-}[71]$ :

$$
\mathrm{Zn}(\mathrm{s})+4 \mathrm{OH}^{-}(\mathrm{aq}) \rightleftharpoons \mathrm{Zn}(\mathrm{OH})_{4}{ }^{2-}(\mathrm{aq})+2 \mathrm{e}^{-} .
$$

Zinc oxide $\mathrm{ZnO}$ precipitates when the critical saturation of zincate in the solution is reached:

$$
\mathrm{Zn}(\mathrm{OH})_{4}{ }^{2-}(\mathrm{aq}) \longrightarrow \mathrm{ZnO}(\mathrm{s})+\mathrm{H}_{2} \mathrm{O}(\mathrm{l})+2 \mathrm{OH}^{-}(\mathrm{aq}) \text {. }
$$


The consumption of hydroxide ions $\mathrm{OH}^{-}$at the anode is recovered in parallel by the conversion of ambient oxygen $\mathrm{O}_{2}$ and water $\mathrm{H}_{2} \mathrm{O}$ to hydroxide ions at the cathode:

$$
\frac{1}{2} \mathrm{O}_{2}(\mathrm{~g})+\mathrm{H}_{2} \mathrm{O}(\mathrm{l})+2 \mathrm{e}^{-} \longrightarrow 2 \mathrm{OH}^{-}(\mathrm{aq}) \text {. }
$$

\subsubsection{Operating Phase I}

Operating phase I specifies three processes, i.e., I.1, I.2 and I.3, at the initial stage of discharge. Stamm et al. have interpreted process I.2 as a linear increase in zincate concentration and a consumption of hydroxide ions in the anode (see Equation (16)), resulting in a linear voltage drop until the electrolyte was supersaturated [72]. Furthermore, they also have justified Process I.3, which was related to the precipitation of zincate to zinc oxide (see Equation (17)) and thus have increased the hydroxide ions and have reduced the overpotential. Relating these findings to the DRT in Figure 9b, zincate formation I.2 can be applied to the time constant $\log \left(\tau_{\mathrm{I} .2}\right) \approx-2.5$ and oxidation of zinc can be applied to the time constant $\log \left(\tau_{\mathrm{I} .3}\right) \approx-1.5$. Process I.1 was related to the time constant $\log \left(\tau_{\mathrm{I} .1}\right) \approx-3$ and was responsible for the second semicircle within the EIS measurement (cf. Figure 8a). Ma et al. have also observed a second semicircle, which have disappeared with higher superimposed discharge currents or already used cathodes [73]. They have explained the second semicircle with the kinetics of the cathode. The kinetics of a chemical reaction can be described by the reaction rate, which depends, e.g., on the temperature, the concentration or the applied catalysts. Figure 11a demonstrates that although the process I.1 is less dominant at very low temperatures, it decays with similar time steps. Furthermore, the peak is only identifiable at $100 \% \mathrm{SoC}$ in the DRT even if the cell was relaxed after the discharge steps. Therefore, we hypothesize that the process I.1 describes less the kinetics and more an initial chemical activation of the cathode.

\subsubsection{Operating Phase II}

In operating phase II, an equilibrium of the presented reactions (16)-(18) has already been reached. A constant deposition of zinc oxide follows, as long as no passivation occurs within the porous anode [15] or secondary processes occur in the cathode, e.g., flooding [74] or pore clogging [75]. The DRT in Figure 7 shows no significant variation between 20 and $70 \%$ discharge capacity and currents up to a maximum of $4 \mathrm{~mA}$, which is a characteristic of stable and constant reactions. Since the process with time constant $\log (\tau) \approx 1$ can be assigned to diffusion [37], the peak $\log (\tau) \approx-1$ is distinctive for oxidation of zinc and the peak $\log (\tau) \approx-4.5$ represents the recovery of hydroxide ions at the cathode.

\subsubsection{Operating Phase III and IV}

Operating phase III represents the voltage step during discharge that was detectable for currents above $3 \mathrm{~mA}$. Two theories have been proposed for this behavior. The first has discussed two different oxidation states of zinc, i.e., "solid-state" and "dissolutionprecipitation" [15]. In this case, the "solid-state" oxidation was observable only at higher overpotentials, which could be caused by higher discharge currents or by depletion of hydroxide ions in the anode. The second study has attributed the voltage step to the inhomogeneous nucleation of the zinc oxide [72]. Specifically, the simulation has shown that the zincate has precipitated near the current collector rather than at the separator and thus has coated the unused zinc with an oxide layer. Overcoming the oxide layer in the later discharge process, was the reason for the voltage drop. The latter study does not coincide with tomography images of the discharge process of ZABs, where a significant oxidation of the zinc accompanied by a shape change have begun near the separator [76,77]. Therefore, we assume that the voltage step is caused by a hindered mass transport due to shape change and volume expansion. Figure 10c shows that with higher currents or at the end of the discharge (cf. Figure 10b), the oxidation process merged into the diffusion process. The operating phase IV is finally the termination of the zinc oxidation (see Figure 10b), which is caused by the complete consumption of zinc or by the formation of a diffusion barrier. 


\subsection{Temperature}

Decreasing the ambient temperature has a similar effect on the discharge capacity as increasing the current. The lower the temperature, the higher the ohmic overpotential and the lower the capacity (cf. Figures 6 and A4). The ambient temperature in general has a complex influence on the entire system, i.e., on all transport processes, on reaction kinetics, on reaction potentials and overpotentials and on the material properties [78]. The electrolyte contributes most to the decreasing potential as the temperature decreases [70], e.g., conductivity decreases approximately linearly with decreasing temperatures [79]. According to the Einstein relation, diffusion is hindered to the same extent, which can lead to limited utilization of the zinc anode at a constant current. The DRT in Figure 12 reveals that the oxidation of zinc was suppressed by lower temperatures and that the diffusion process was nearly constant. Figure 11 also shows that activation of the cathode was tremendously inhibited by temperatures below $273 \mathrm{~K}$.

\subsection{Shortcomings}

Figure 8a shows an ECM that is sometimes used for modeling of ZABs or subprocesses [26,80-82]. This ECM provides good results here for $100 \%$ SoC (see Figure 8c). However, with the disappearance of the second semicircle after $1 \%$ discharge, the model is overparameterized and thus, without any further adaption, unsuitable (see Figure 8d). The DRT, on the other hand, provides an approach that bypasses an accurate knowledge of a suitable model. With appropriate post-processing functions, individual parameters can also be quantified as shown in Table 2. For a correct quantification, however, some parameters of the DRT have to be considered critically:

- The regularization parameter directly influences the number and heights of the peaks within the DRT (see Figure A3). Each EIS measurement may have its own optimal regularization parameter, so that an estimation of the parameter must be made over all data (cf. Figure 5). It is not guaranteed that there will be an ideal parameter for the entire data set.

- The intersection of the EIS measurement with the real axis is not always given at high frequencies and no $\Im\left\{Z_{\text {Meas }}\right\}=0$ exists. The intersection point for the DRT must consequently be estimated for the initial condition, which leads to an additional peak and a minimization of the other peaks according to Equation (12). This shortcoming can be avoided by pre-processing the EIS measurement.

- The extended time constant range and the extended boundary at low frequencies improve the physical interpretation of the DRT but manipulate the height of the peaks.

\section{Conclusions}

The applicability of the DRT to the process analysis of ZABs was confirmed for the first time. The findings and the simulations from the literature could be covered by the DRT, which opens up new possibilities in the simulation and analysis of ZABs. For example, the cathode activation process and also the current dependence of the oxidation of zinc could be identified by this technique. The method presented here for the determination of the regularization parameter is based on the comparison of the reconstructed data from a Gaussian probability distribution function and the impedance values from the EIS measurement. This method can provide a good estimate of a suitable regularization parameter, but should always be verified in terms of plausibility with the available measurements. Since the capacity spread of the primary cells were wide, which made it difficult to approach the targeted SoC values, future studies should use only a repeating EIS with superimposed current and should calculate the capacity retrospectively. 
Author Contributions: Conceptualization, R.F.-L.; methodology, R.F.-L.; software, R.F.-L.; validation, R.F.-L.; formal analysis, R.F.-L.; investigation, R.F.-L.; resources, R.F.-L.; data curation, R.F.-L.; writing—original draft preparation, R.F.-L.; writing-review and editing, R.F.-L.; visualization, R.F.-L.; supervision, J.K. Both authors have read and agreed to the published version of the manuscript.

Funding: This research received no external funding.

Institutional Review Board Statement: Not applicable.

Informed Consent Statement: Not applicable.

Data Availability Statement: Data available on request from the authors.

Acknowledgments: We gratefully acknowledge Adriel Alexandro Santoso for monitoring and performing the EIS measurements.

Conflicts of Interest: The authors declare no conflict of interest.

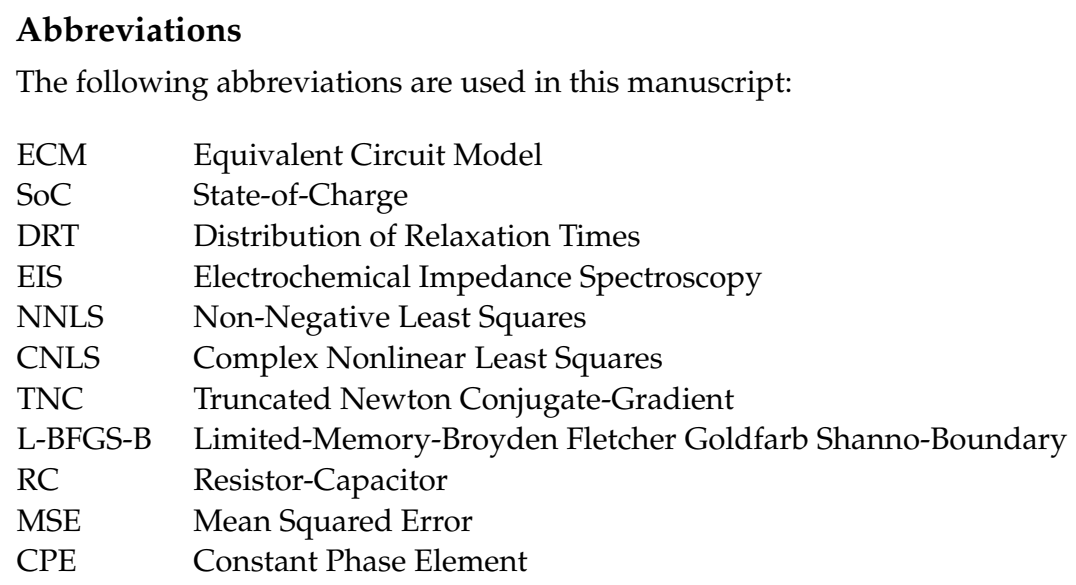

Appendix A. Theory

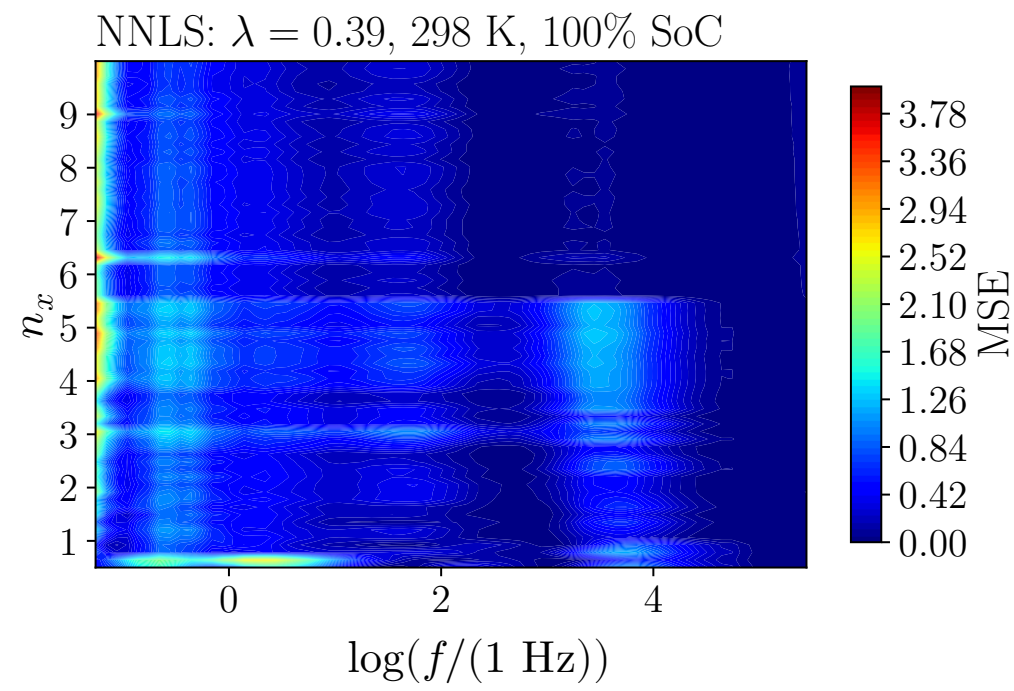

Figure A1. Influence of the number of sample points as mean squared error (MSE) between measurement and reconstruction for EIS measurement of a ZAB at $298 \mathrm{~K}$ and SoC of $100 \%$. The numbers $n$ correspond to multiples of the number of frequency points $m$. 


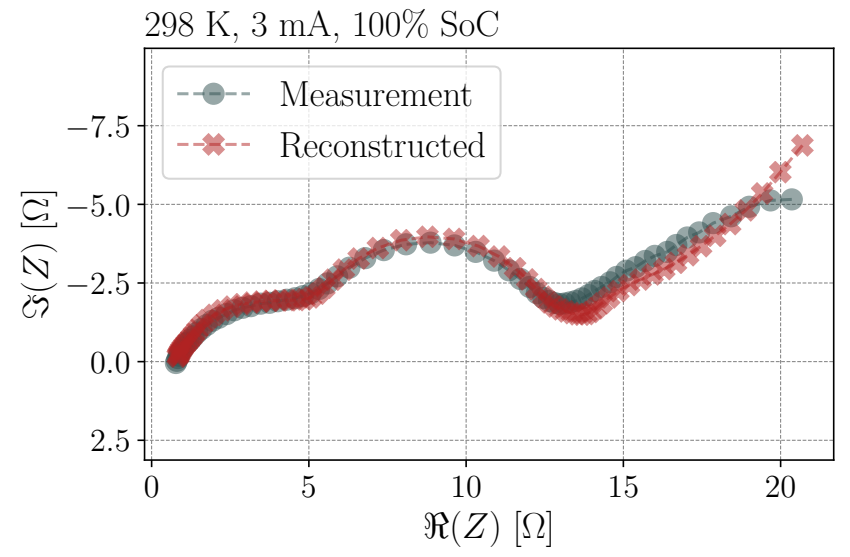

(a) Extended range of time constants

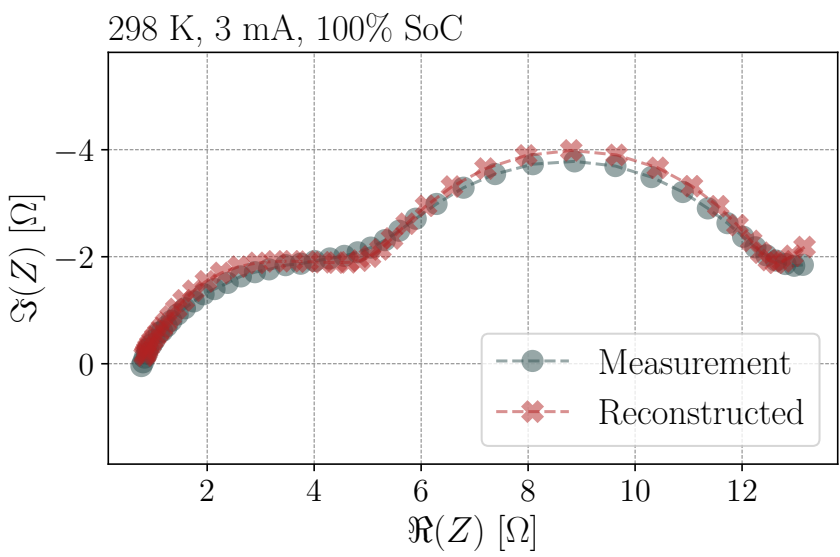

(c) Excluded diffusion part

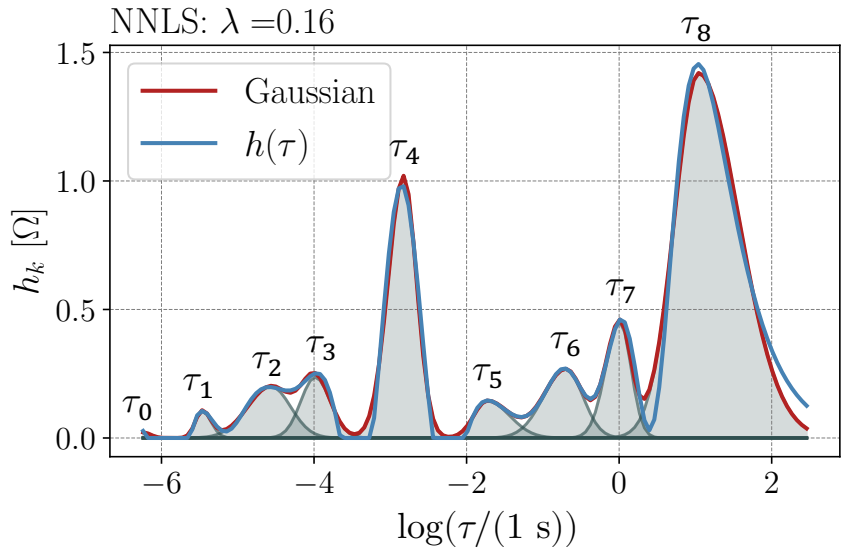

(b) Extended range of time constants

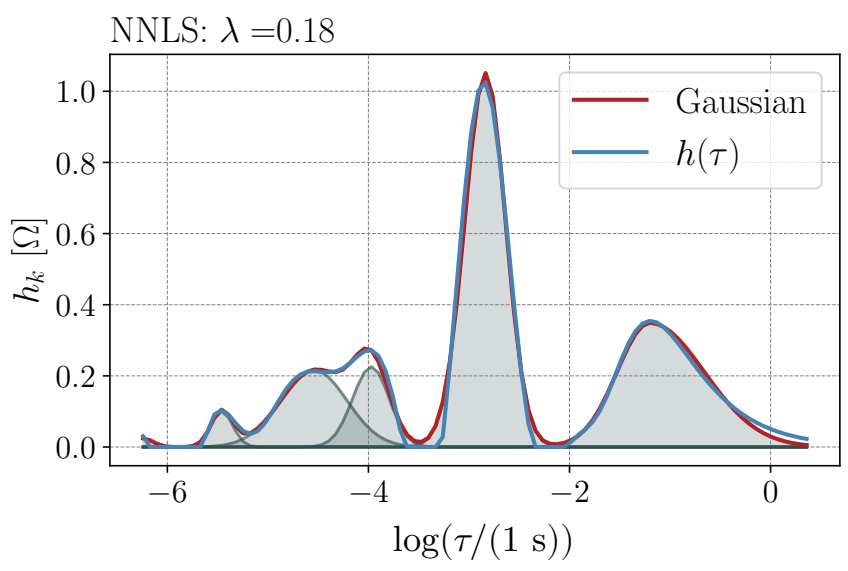

(d) Excluded diffusion part

Figure A2. Improvement of DRT based on the extension of the time constant range $(\mathbf{a}, \mathbf{b})$ and on the exclusion of the diffusion parts $(\mathbf{c}, \mathbf{d})$. The EIS and the reconstructed impedance spectrum related to the DRT is depicted in $(\mathbf{a}, \mathbf{c})$ and the corresponding DRT in $(\mathbf{b}, \mathbf{d})$.

\section{Appendix B. Results}

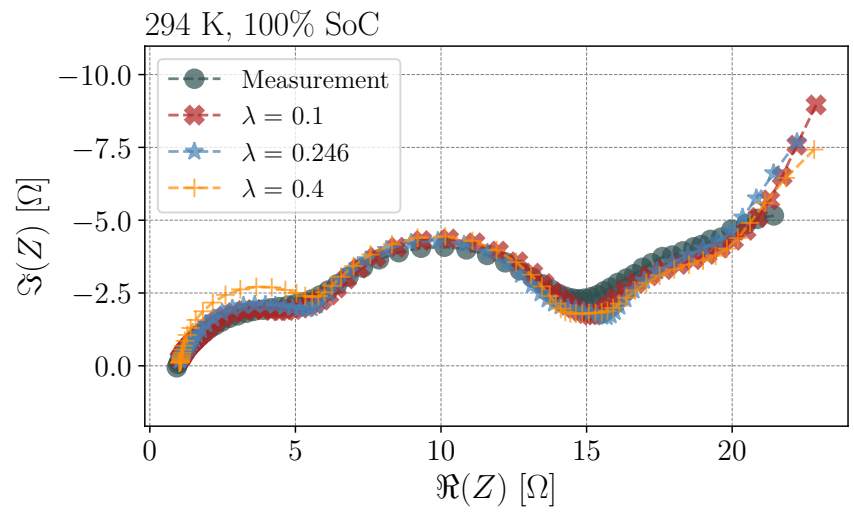

(a) EIS

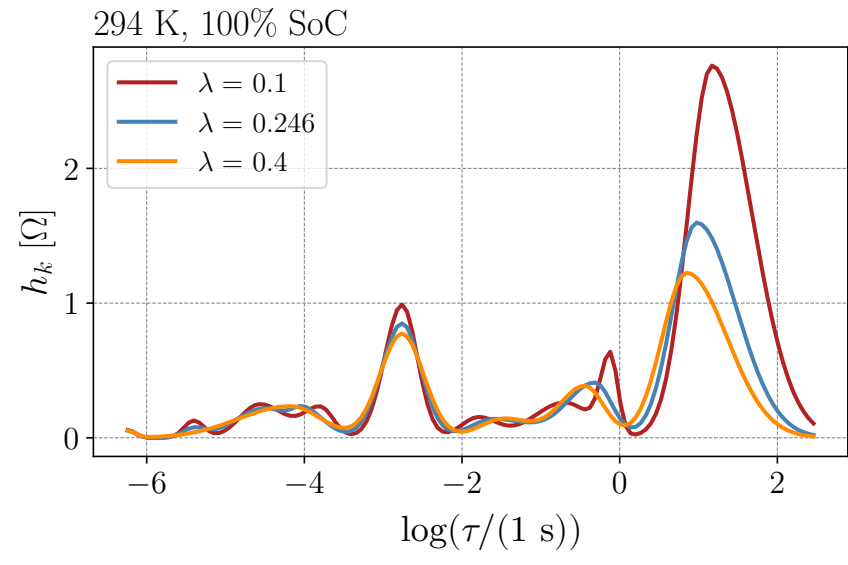

(b) DRT

Figure A3. Influence of the regularization parameter on the reconstruction of the impedance data (a) from the DRT (b). 


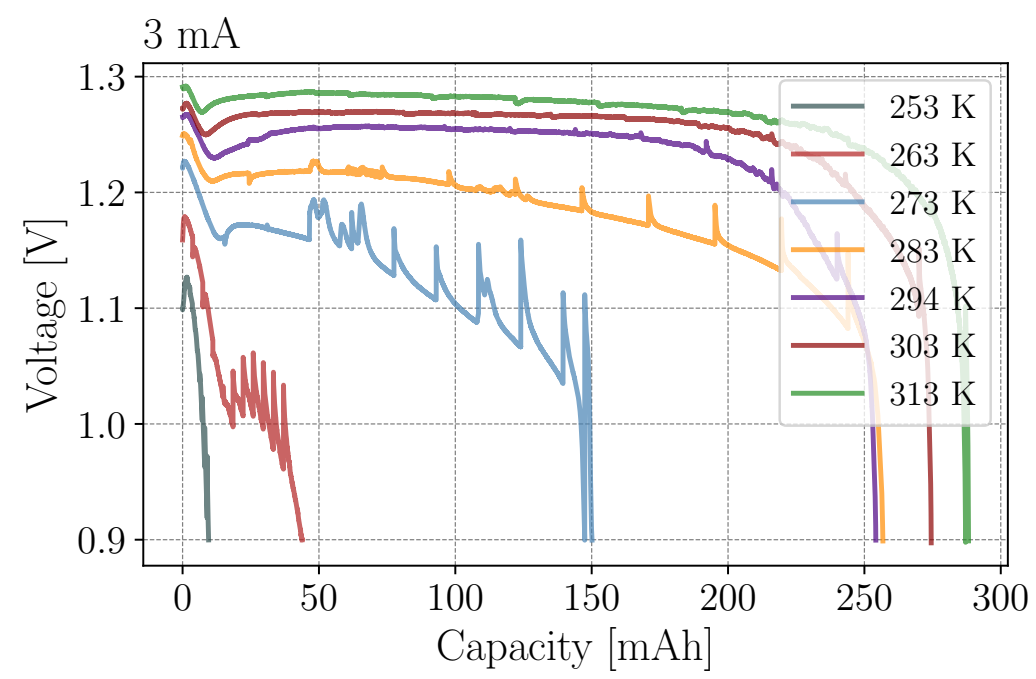

Figure A4. ZAB PR48 concatenated discharge profiles at $3 \mathrm{~mA}$ and various temperatures from $253 \mathrm{~K}$ to $313 \mathrm{~K}$. The rest phases and the EIS measurements were removed from the data resulting in peak artifacts.

Table A1. Fitted ECM values from the EIS measurements shown in Figure 8c,d.

\begin{tabular}{lccccccccc}
\hline SoC & $\boldsymbol{R}_{\mathbf{0}}$ in $\boldsymbol{\Omega}$ & $\boldsymbol{R}_{\mathbf{1}}$ in $\boldsymbol{\Omega}$ & $\boldsymbol{R}_{\mathbf{2}}$ in $\boldsymbol{\Omega}$ & $\boldsymbol{Q}_{\mathbf{1}}$ in $\mathbf{S} \mathbf{~ s}^{\mathbf{n}}$ & $\boldsymbol{Q}_{\mathbf{2}}$ in $\mathbf{S ~ \mathbf { s } ^ { \mathbf { n } }}$ & $\boldsymbol{Q}_{\mathbf{3}}$ in $\mathbf{S} \mathbf{s}^{\mathbf{n}}$ & $\boldsymbol{n}_{\mathbf{1}}$ & $\boldsymbol{n}_{\mathbf{2}}$ & $\boldsymbol{n}_{\mathbf{3}}$ \\
\hline $100 \%$ & 0.80 & 5.36 & 5.37 & $9.4 \times 10^{-5}$ & $1.8 \times 10^{-4}$ & $1.6 \times 10^{-2}$ & 0.77 & 1.03 & 0.80 \\
$98.76 \%$ & 0.89 & 3.22 & 3.22 & $2.0 \times 10^{-5}$ & $1.8 \times 10^{-4}$ & $4.6 \times 10^{-2}$ & 0.90 & 0.88 & 0.58 \\
\hline
\end{tabular}

\section{References}

1. Li, M.; Lu, J.; Chen, Z.; Amine, K. 30 Years of Lithium-Ion Batteries. Adv. Mater. 2018, 30, 1800561. [CrossRef]

2. Caramia, V.; Bozzini, B. Materials science aspects of zinc-air batteries: A review. Mater. Renew. Sustain. Energy 2014, 3, 28. [CrossRef]

3. Yi, J.; Liang, P.; Liu, X.; Wu, K.; Liu, Y.; Wang, Y.; Xia, Y.; Zhang, J. Challenges, mitigation strategies and perspectives in development of zinc-electrode materials and fabrication for rechargeable zinc-air batteries. Energy Environ. Sci. 2018, 11, 3075-3095. [CrossRef]

4. $\quad$ Pan, J.; Xu, Y.Y.; Yang, H.; Dong, Z.; Liu, H.; Xia, B.Y. Advanced Architectures and Relatives of Air Electrodes in Zn-Air Batteries. Adv. Sci. 2018, 5, 1700691. [CrossRef]

5. Zhang, J.; Zhou, Q.; Tang, Y.; Zhang, L.; Li, Y. Zinc-air batteries: Are they ready for prime time? Chem. Sci. 2019, 10, 8924-8929. [CrossRef] [PubMed]

6. $\quad$ Fu, J.; Cano, Z.P.; Park, M.G.; Yu, A.; Fowler, M.; Chen, Z. Electrically Rechargeable Zinc-Air Batteries: Progress, Challenges, and Perspectives. Adv. Mater. 2017, 29, 1604685. [CrossRef] [PubMed]

7. Pei, P.; Wang, K.; Ma, Z. Technologies for extending zinc-air battery's cyclelife: A review. Appl. Energy 2014, 128, 315-324. [CrossRef]

8. Gu, P.; Zheng, M.; Zhao, Q.; Xiao, X.; Xue, H.; Pang, H. Rechargeable zinc-air batteries: A promising way to green energy. J. Mater. Chem. A 2017, 5, 7651-7666. [CrossRef]

9. Shin, J.; Lee, J.; Park, Y.; Choi, J.W. Aqueous zinc ion batteries: Focus on zinc metal anodes. Chem. Sci. 2020, 11, 2028-2044. [CrossRef]

10. Stock, D.; Dongmo, S.; Damtew, D.; Stumpp, M.; Konovalova, A.; Henkensmeier, D.; Schlettwein, D.; Schröder, D. Design Strategy for Zinc Anodes with Enhanced Utilization and Retention: Electrodeposited Zinc Oxide on Carbon Mesh Protected by Ionomeric Layers. ACS Appl. Energy Mater. 2018, 1, 5579-5588. [CrossRef]

11. Riede, J.C.; Turek, T.; Kunz, U. Critical zinc ion concentration on the electrode surface determines dendritic zinc growth during charging a zinc air battery. Electrochim. Acta 2018, 269, 217-224. [CrossRef]

12. Mainar, A.R.; Colmenares, L.C.; Grande, H.J.J.; Blázquez, J.A. Enhancing the cycle life of a Zinc-air battery by means of electrolyte additives and zinc surface protection. Batteries 2018, 4, 46. [CrossRef]

13. Mainar, A.R.; Colmenares, L.C.; Blázquez, J.A.; Urdampilleta, I. A brief overview of secondary zinc anode development: The key of improving zinc-based energy storage systems. Int. J. Energy Res. 2018, 42, 903-918. [CrossRef] 
14. Stock, D.; Dongmo, S.; Walther, F.; Sann, J.; Janek, J.; Schröder, D. Homogeneous Coating with an Anion-Exchange Ionomer Improves the Cycling Stability of Secondary Batteries with Zinc Anodes. ACS Appl. Mater. Interfaces 2018, 10, 8640-8648. [CrossRef]

15. Bockelmann, M.; Becker, M.; Reining, L.; Kunz, U.; Turek, T. Passivation of Zinc Anodes in Alkaline Electrolyte: Part I. Determination of the Starting Point of Passive Film Formation. J. Electrochem. Soc. 2018, 165, A3048-A3055. [CrossRef]

16. Bockelmann, M.; Becker, M.; Reining, L.; Kunz, U.; Turek, T. Passivation of Zinc Anodes in Alkaline Electrolyte: Part II. Influence of Operation Parameters. J. Electrochem. Soc. 2019, 166, A1132-A1139. [CrossRef]

17. Cai, M.; Park, S.M. Spectroelectrochemical Studies on Dissolution and Passivation of Zinc Electrodes in Alkaline Solutions. J. Electrochem. Soc. 1996, 143, 2125. [CrossRef]

18. Kim, H.I.; Kim, E.J.; Kim, S.J.; Shin, H.C. Influence of ZnO precipitation on the cycling stability of rechargeable Zn-air batteries. J. Appl. Electrochem. 2015, 45, 335-342. [CrossRef]

19. Franke-Lang, R.; Arlt, T.; Manke, I.; Kowal, J. X-ray tomography as a powerful method for zinc-air battery research. J. Power Sources 2017, 370, 45-51. [CrossRef]

20. Wang, H.F.; Xu, Q. Materials Design for Rechargeable Metal-Air Batteries. Matter 2019, 1, 565-595. [CrossRef]

21. Macdonald, J.R. Impedance spectroscopy. Ann. Biomed. Eng. 1992, 20, 289-305. [CrossRef] [PubMed]

22. Fu, J.; Zhang, J.; Song, X.; Zarrin, H.; Tian, X.; Qiao, J.; Rasen, L.; Li, K.; Chen, Z. A flexible solid-state electrolyte for wide-scale integration of rechargeable zinc-air batteries. Energy Environ. Sci. 2016, 9, 663-670. [CrossRef]

23. Sanal, E.; Dost, P.; Sourkounis, C. Electrotechnical investigation of zinc-air cells for determination of cell-parameters for a battery management system. In Proceedings of the 2015 International Conference on Renewable Energy Research and Applications (ICRERA), Palermo, Italy, 22-25 November 2015; pp. 1157-1161. [CrossRef]

24. Larsson, F.; Rytinki, A.; Ahmed, I.; Albinsson, I.; Mellander, B.E. Overcurrent abuse of primary prismatic zinc-air battery cells studying air supply effects on performance and safety shut-down. Batteries 2017, 3, 1. [CrossRef]

25. Meng, F.; Zhong, H.; Bao, D.; Yan, J.; Zhang, X. In Situ Coupling of Strung Co 4 N and Intertwined N-C Fibers toward Free-Standing Bifunctional Cathode for Robust, Efficient, and Flexible Zn-Air Batteries. J. Am. Chem. Soc. 2016, 138, 10226-10231. [CrossRef] [PubMed]

26. Li, G.; Zhang, K.; Mezaal, M.A.; Zhang, R.; Lei, L. Effect of electrolyte concentration and depth of discharge for zinc-air fuel cell. Int. J. Electrochem. Sci. 2015, 10, 6672-6683.

27. Chotipanich, J.; Arpornwichanop, A.; Yonezawa, T.; Kheawhom, S. Electronic and ionic conductivities enhancement of zinc anode for flexible printed zinc-air battery. Eng. J. 2018, 22, 47-57. [CrossRef]

28. Kubannek, F.; Turek, T.; Krewer, U. Modeling Oxygen Gas Diffusion Electrodes for Various Technical Applications. ChemieIngenieur-Technik 2019, 91, 720-733. [CrossRef]

29. Tran, T.N.T.; Chung, H.J.; Ivey, D.G. A study of alkaline gel polymer electrolytes for rechargeable zinc-air batteries. Electrochim. Acta 2019, 327, 135021. [CrossRef]

30. Barsoukov, E.; Macdonald, J.R. (Eds.) Impedance Spectroscopy, 3rd ed.; John Wiley \& Sons, Inc.: Hoboken, NJ, USA, 2018; pp. 1-528. [CrossRef]

31. Vielstich, W.; Hamann, C.H. Elektrochemie; Wiley-VCH: Weinheim, Germany, 2005; p. 662. [CrossRef]

32. Weiß, A.; Schindler, S.; Galbiati, S.; Danzer, M.A.; Zeis, R. Distribution of Relaxation Times Analysis of High-Temperature PEM Fuel Cell Impedance Spectra. Electrochim. Acta 2017, 230, 391-398. [CrossRef]

33. Ivers-Tiffée, E.; Weber, A. Evaluation of electrochemical impedance spectra by the distribution of relaxation times. J. Ceram. Soc. Jpn. 2017, 125, 193-201. [CrossRef]

34. Schichlein, H.; Müller, A.C.; Voigts, M.; Krügel, A.; Ivers-Tiffée, E. Deconvolution of electrochemical impedance spectra for the identification of electrode reaction mechanisms in solid oxide fuel cells. J. Appl. Electrochem. 2002, 32, 875-882.:1020599525160. [CrossRef]

35. Hahn, M.; Schindler, S.; Triebs, L.C.; Danzer, M.A. Optimized process parameters for a reproducible distribution of relaxation times analysis of electrochemical systems. Batteries 2019, 5, 43. [CrossRef]

36. Hahn, M.; Rosenbach, D.; Krimalowski, A.; Nazarenus, T.; Moos, R.; Thelakkat, M.; Danzer, M.A. Investigating solid polymer and ceramic electrolytes for lithium-ion batteries by means of an extended Distribution of Relaxation Times analysis. Electrochim. Acta 2020, 344, 136060. [CrossRef]

37. Danzer, M.A. Generalized distribution of relaxation times analysis for the characterization of impedance spectra. Batteries 2019, 5, 53. [CrossRef]

38. Ciucci, F.; Chen, C. Analysis of electrochemical impedance spectroscopy data using the distribution of relaxation times: A Bayesian and hierarchical Bayesian approach. Electrochim. Acta 2015, 167, 439-454. [CrossRef]

39. Schlüter, N.; Ernst, S.; Schröder, U. Direct Access to the Optimal Regularization Parameter in Distribution of Relaxation Times Analysis. ChemElectroChem 2020, 7, 3445-3458. [CrossRef]

40. Boukamp, B.A. Fourier transform distribution function of relaxation times; application and limitations. Electrochim. Acta 2015, 154, 35-46. [CrossRef]

41. Boukamp, B.A.; Rolle, A. Analysis and Application of Distribution of Relaxation Times in Solid State Ionics. Solid State Ion. 2017, 302, 12-18. [CrossRef] 
42. Effat, M.B.; Ciucci, F. Bayesian and Hierarchical Bayesian Based Regularization for Deconvolving the Distribution of Relaxation Times from Electrochemical Impedance Spectroscopy Data. Electrochim. Acta 2017, 247, 1117-1129. [CrossRef]

43. Hörlin, T. Deconvolution and maximum entropy in impedance spectroscopy of noninductive systems. Solid State Ion. 1998, 107, 241-253. [CrossRef]

44. Liu, J.; Ciucci, F. The Gaussian process distribution of relaxation times: A machine learning tool for the analysis and prediction of electrochemical impedance spectroscopy data. Electrochim. Acta 2020, 331, 135316. [CrossRef]

45. Liu, J.; Ciucci, F. The Deep-Prior Distribution of Relaxation Times. J. Electrochem. Soc. 2020, 167, 026506. [CrossRef]

46. Tuncer, E.; Gubanski, S. On dielectric data analysis. Using the Monte Carlo method to obtain relaxation time distribution and comparing non-linear spectral function fits. IEEE Trans. Dielectr. Electr. Insul. 2001, 8, 310-320. [CrossRef]

47. Ross Macdonald, J. Comparison of parametric and nonparametric methods for the analysis and inversion of immittance data: Critique of earlier work. J. Comput. Phys. 2000, 157, 280-301. [CrossRef]

48. Bello, A.; Laredo, E.; Grimau, M. Distribution of relaxation times from dielectric spectroscopy using Monte Carlo simulated annealing: $\alpha$-PVDF. Phys. Rev. B 1999, 60, 12764-12774. [CrossRef]

49. Tesler, A.B.; Lewin, D.R.; Baltianski, S.; Tsur, Y. Analyzing results of impedance spectroscopy using novel evolutionary programming techniques. J. Electroceram. 2010, 24, 245-260. [CrossRef]

50. Hershkovitz, S.; Baltianski, S.; Tsur, Y. Harnessing evolutionary programming for impedance spectroscopy analysis: A case study of mixed ionic-electronic conductors. Solid State Ion. 2011, 188, 104-109. [CrossRef]

51. Saccoccio, M.; Wan, T.H.; Chen, C.; Ciucci, F. Optimal regularization in distribution of relaxation times applied to electrochemical impedance spectroscopy: Ridge and Lasso regression methods-A theoretical and experimental Study. Electrochim. Acta 2014, 147, 470-482. [CrossRef]

52. Wan, T.H.; Saccoccio, M.; Chen, C.; Ciucci, F. Influence of the Discretization Methods on the Distribution of Relaxation Times Deconvolution: Implementing Radial Basis Functions with DRTtools. Electrochim. Acta 2015, 184, 483-499. [CrossRef]

53. Žic, M.; Pereverzyev, S.; Subotić, V.; Pereverzyev, S. Adaptive multi-parameter regularization approach to construct the distribution function of relaxation times. GEM Int. J. Geomath. 2020, 11, 1-23. [CrossRef] [PubMed]

54. Gavrilyuk, A.L.; Osinkin, D.A.; Bronin, D.I. The use of Tikhonov regularization method for calculating the distribution function of relaxation times in impedance spectroscopy. Russ. J. Electrochem. 2017, 53, 575-588. [CrossRef]

55. Schlüter, N.; Ernst, S.; Schröder, U. Finding the Optimal Regularization Parameter in Distribution of Relaxation Times Analysis. ChemElectroChem 2019, 6, 6027-6037. [CrossRef]

56. Li, X.; Ahmadi, M.; Collins, L.; Kalinin, S.V. Deconvolving distribution of relaxation times, resistances and inductance from electrochemical impedance spectroscopy via statistical model selection: Exploiting structural-sparsity regularization and datadriven parameter tuning. Electrochim. Acta 2019, 313, 570-583. [CrossRef]

57. Nickol, A.; Schied, T.; Heubner, C.; Schneider, M.; Michaelis, A.; Bobeth, M.; Cuniberti, G. GITT Analysis of Lithium Insertion Cathodes for Determining the Lithium Diffusion Coefficient at Low Temperature: Challenges and Pitfalls. J. Electrochem. Soc. 2020, 167, 090546. [CrossRef]

58. Lawson, C.L.; Hanson, R.J. Solving Least Squares Problems; Society for Industrial and Applied Mathematics: Philadelphia, PA, USA, 1995; p. 337. [CrossRef]

59. Marquardt, D.W. An Algorithm for Least-Squares Estimation of Nonlinear Parameters. J. Soc. Ind. Appl. Math. 1963, 11, 431-441. [CrossRef]

60. Kraft, D. A Software Package for Sequential Quadratic Programming; Wiss. Berichtswesen d. DFVLR: Köln, Germany, 1988.

61. Byrd, R.H.; Lu, P.; Nocedal, J.; Zhu, C. A Limited Memory Algorithm for Bound Constrained Optimization. SIAM J. Sci. Comput. 1995, 16, 1190-1208. [CrossRef]

62. Tikhonov, A.N.; Goncharsky, A.V.; Stepanov, V.V.; Yagola, A.G. Numerical Methods for the Solution of Ill-Posed Problems; Springer: Dordrecht, The Netherlands, 1995; doi:10.1007/978-94-015-8480-7. [CrossRef]

63. Hansen, J.K.; Hogue, J.D.; Sander, G.K.; Renaut, R.A.; Popat, S.C. Non-negatively constrained least squares and parameter choice by the residual periodogram for the inversion of electrochemical impedance spectroscopy data. J. Comput. Appl. Math. 2015, 278, 52-74. [CrossRef]

64. Korth Pereira Ferraz, P.; Kowal, J. A Comparative Study on the Influence of DC/DC-Converter Induced High Frequency Current Ripple on Lithium-Ion Batteries. Sustainability 2019, 11, 6050. [CrossRef]

65. Agarwal, P.; Orazem, M. Measurement Models for Electrochemical Impedance Spectroscopy. J. Electrochem. Soc. 1992, $139,1917$. [CrossRef]

66. Orazem, M.E.; Tribollet, B. Electrochemical Impedance Spectroscopy; John Wiley \& Sons, Inc.: Hoboken, NJ, USA, 2017 ; pp. 1-523. [CrossRef]

67. Deutsches Institut für Normung e.V. International Standard: Primary Batteries_Part 2: Physical and Electrical Specifications (IEC 60086-2:2015); Beuth-Verlag: Berlin, Germany2016; doi:10.31030/2535128. [CrossRef]

68. Ingale, P.; Sakthivel, M.; Drillet, J.F. Test of Diethylmethylammonium Trifluoromethanesulfonate Ionic Liquid as Electrolyte in Electrically Rechargeable Zn/Air Battery. J. Electrochem. Soc. 2017, 164, H5224-H5229. [CrossRef]

69. Penteado, S.P.; Bento, R.F. Performance analysis of ten brands of batteries for hearing aids. Int. Arch. Otorhinolaryngol. 2013, 17, 291-304. [CrossRef]

70. Reddy, T.B. Linden's Handbook of Batteries, 4th ed.; McGraw-Hill Education: New York, NY, USA, 2011. 
71. Clark, S.; Mainar, A.R.; Iruin, E.; Colmenares, L.C.; Blázquez, J.A.; Tolchard, J.R.; Jusys, Z.; Horstmann, B. Designing Aqueous Organic Electrolytes for Zinc-Air Batteries: Method, Simulation, and Validation. Adv. Energy Mater. 2020, 10. [CrossRef]

72. Stamm, J.; Varzi, A.; Latz, A.; Horstmann, B. Modeling nucleation and growth of zinc oxide during discharge of primary zinc-air batteries. J. Power Sources 2017, 360, 136-149. [CrossRef]

73. Ma, Z.; Pei, P.; Wang, K.; Wang, X.; Xu, H.; Liu, Y.; Peng, G. Degradation characteristics of air cathode in zinc air fuel cells. J. Power Sources 2015, 274, 56-64. [CrossRef]

74. Schröder, D.; Arlt, T.; Krewer, U.; Manke, I. Analyzing transport paths in the air electrode of a zinc air battery using X-ray tomography. Electrochem. Commun. 2014, 40, 88-91. [CrossRef]

75. Tsehaye, M.T.; Alloin, F.; Iojoiu, C.; Tufa, R.A.; Aili, D.; Fischer, P.; Velizarov, S. Membranes for zinc-air batteries: Recent progress, challenges and perspectives. J. Power Sources 2020, 475, 228689. [CrossRef]

76. Schmitt, T.; Arlt, T.; Manke, I.; Latz, A.; Horstmann, B. Zinc electrode shape-change in secondary air batteries: A 2D modeling approach. J. Power Sources 2019, 432, 119-132. [CrossRef]

77. Arlt, T.; Schröder, D.; Krewer, U.; Manke, I. In operando monitoring of the state of charge and species distribution in zinc air batteries using X-ray tomography and model-based simulations. Phys. Chem. Chem. Phys. 2014, 16, 22273-22280. [CrossRef] [PubMed]

78. Franke-lang, R.; Kowal, J. Electrochemical Model-Based Investigation of Thick $\mathrm{LiFePO}_{4}$ Electrode Design Parameters. Modelling 2021, 2, 259-287. [CrossRef]

79. See, D.M.; White, R.E. Temperature and concentration dependence of the specific conductivity of concentrated solutions of potassium hydroxide. J. Chem. Eng. Data 1997, 42, 1266-1268. [CrossRef]

80. Zhuang, S.; Zhang, H.; Liu, S.; Tu, F.; Zhang, W.; Zhao, C. Optimized perovskite electrocatalyst for bifunctional air electrode by impedance spectroscopy analysis. Int. J. Electrochem. Sci. 2014, 9, 1690-1701.

81. Hoang, T.K.A.; Doan, T.N.L.; Sun, K.E.K.; Chen, P. Corrosion chemistry and protection of zinc \& zinc alloys by polymer-containing materials for potential use in rechargeable aqueous batteries. RSC Adv. 2015, 5, 41677-41691. [CrossRef]

82. Thomas Goh, F.W.; Liu, Z.; Hor, T.S.A.; Zhang, J.; Ge, X.; Zong, Y.; Yu, A.; Khoo, W. A Near-Neutral Chloride Electrolyte for Electrically Rechargeable Zinc-Air Batteries. J. Electrochem. Soc. 2014, 161, A2080-A2086. [CrossRef] 